\title{
Cantharidin-Loaded Biomimetic MOF Nanoparticles Cascade To Enhance Fenton Reaction Based On Amplified Photothermal Therapy
}

\section{Xiao Cheng}

Dalian University of Technology

Ye Liu

Dalian University of Technology

Hao Zhou

Dalian University of Technology

Junke Leng

Dalian University of Technology

\section{Xiaofeng Dai}

Dalian University of Technology

\section{Dong Wang}

Panjin People's Hospital

\section{Kun Ma}

Dalian University of Technology

Changhao Cui

Dalian University of Technology

Jijun Fu

Guangzhou Medical University

Zhaoming Guo ( $\square$ guozm@dlut.edu.cn )

Dalian University of Technology https://orcid.org/0000-0003-1295-6838

\section{Research}

Keywords: Metal organic framework (MOF), Tumour microenvironment (TME), Fenton reaction, Photothermal therapy (PTT), Heat shock response (HSR)

Posted Date: June 8th, 2021

DOI: https://doi.org/10.21203/rs.3.rs-575033/v1

License: (c) (1) This work is licensed under a Creative Commons Attribution 4.0 International License. 
Version of Record: A version of this preprint was published at Biomaterials Science on January 1st, 2021. See the published version at https://doi.org/10.1039/D1BM01396C. 


\section{Cantharidin-Loaded Biomimetic MOF}

2 Nanoparticles Cascade to Enhance Fenton

3 Reaction Based on Amplified Photothermal

4 Therapy

5 Xiao Cheng a , Ye Liu ${ }^{\text {a }}$, Hao Zhou ${ }^{\text {b }}$, Junke Leng ${ }^{\text {a }}$, Xiaofeng Dai a , Dong Wang ${ }^{\text {c }}$, Kun

$6 \mathrm{Ma}^{\mathrm{a}}$, Changhao Cui ${ }^{\mathrm{a}}$, Jijun $\mathrm{Fu}{ }^{*, \mathrm{~d}}$, Zhaoming Guo *,a

7 a School of Life and Pharmaceutical Sciences, Dalian University of Technology, Panjin,

8 Liaoning 124221, China

9 b School of Food and Environment, Dalian University of Technology, Panjin, Liaoning

10 124221, China

11 c Panjin People's Hospital, Panjin, Liaoning 124221, China

12 d The Key Laboratory of Molecular Target \& Clinical Pharmacology, The First

13 Affiliated Hospital of Guangzhou Medical University, Guangzhou Medical University,

14 Guangzhou, 511436, China

$15 *$ Corresponding author:

16 School of Life and Pharmaceutical Sciences, Dalian University of Technology, Panjin,

17 Liaoning 124221, China.

18 Tel: +86-427-2631427. Fax: +86-427-2631889. E-mail address: guozm@dlut.edu.cn

19 (Zhaoming Guo) 
21 Hospital of Guangzhou Medical University, Guangzhou Medical University, Guangzhou, 511436, China

Key Words: Metal organic framework (MOF); Tumour microenvironment (TME); Fenton reaction; Photothermal therapy (PTT); Heat shock response (HSR)

\section{ABSTRACT}

The treatment efficiency of Fenton reaction is expected to be greatly restricted due to problems such as inefficient delivery of Fenton catalysis, limited $\mathrm{H}_{2} \mathrm{O}_{2}$ concentration and uneven tumour tissue. Accurate photothermal therapy (PTT) can to some extent

31 improve the efficiency of Fenton catalysis by raising temperature. However, the heat shock response (HSR) of tumour cells caused by PTT and Fenton reaction can attenuate the treatment effect. In this study, we developed a combined treatment platform based on the Fenton reaction mediated by iron ions consisting of a metal organic framework, i.e., PPy-CTD@MIL-100@MPCM nanoparticles (PCMM NPs), and we explored the inhibitory effect of PCMM NPs on the heat shock response (HSR). PCMM NPs can be recruited into tumour tissues through the response of biomacromolecules on the surface of macrophage cell membranes (MPCMs) to tumour cell signaling molecules, thereby increasing retention and accumulation. The photothermal effect of polypyrrole (PPy) can stimulate the HSR of tumour, and loaded HSP inhibitor-cantharidin (CTD) can 
41 inhibit this response to a large extent. In addition, the heat generated during the PTT process can accelerate the release of iron ions from the PCMM NPs and simultaneously

43 improve the efficiency of the Fenton reaction to achieve a combined treatment of 44 tumour PTT, Fenton therapy and chemotherapy.

\section{Introduction}

The tumour microenvironment (TME) closely related to tumours is an extremely complex integrated system that is composed of various stromal cells and extracellular matrix(1). TME with the characteristics of hypoxic, higher levels of glutathione (GSH) and reactive oxygen species (ROS)(2) provides a suitable environment for tumour development. On the other hand, these features furnish an opportunity for some therapy methods to improve anti-tumour capabilities.

Recently, studies have shown that the TME provides an excellent stage for Fenton therapy, a therapeutic strategy mediated by iron ions $(3,4)$. The Fenton reaction can consume excessive $\mathrm{H}_{2} \mathrm{O}_{2}$ in tumour tissue, generate the strongest ROS, i.e., hydroxyl radicals $(5,6)$, to kill tumour cells and simultaneously generate oxygen to improve the hypoxic state of the TME(7). These characteristics are absolutely helpful for inhibiting tumour proliferation and angiogenesis(8). However, Fenton reaction is often inefficient due to the limited $\mathrm{H}_{2} \mathrm{O}_{2}$ concentration, uneven tumour tissue and other conditions (9, 10). Therefore, the Fenton reaction alone is not sufficient to achieve the desired therapeutic effect, and combination therapy is necessary. According to the classic thermodynamic molecular collision theory, increasing the temperature may be a 
62 feasible way to improve the efficiency of the Fenton reaction $(9,11)$. Therefore, accurate

63 and effective PTT can be a good partner(12).

64 The MOF is an excellent platform for combination tumour therapy. Organic 65 polypyrrole (PPy) has the advantages of high photothermal conversion efficiency and good biocompatibility, so we chose it as the central photothermal agent in the MOF

67 (13). Loading $\mathrm{Fe}^{3+}$ as the skeleton of the MOF can achieve the Fenton reaction and consume GSH to downregulate glutathione peroxidase 4 (GPX4) to mediate tumour 69 cell ferroptosis(14).

70 However, damaging treatments such as PTT or Fenton therapy can cause the HSR,

71 which is a general protection mechanism for tumour cells to resist external damage( 15 ,

72 16). This is the key to successfully eradicating tumour that effectively inhibiting tumour 73 HSR in damaging treatments(17). As a therapeutic drug used for treating liver cancer 74 and melanoma, cantharidin (CTD) has been identified in past studies as an inhibitor of 75 heat shock transcription factor 1 (HSF1) and has a good effect on inhibiting the 76 HSR(18). Therefore, we used CTD as a model drug to resist HSR and improve the 77 therapeutic effect. Finally, to improve the targeting and long circulation of 78 nanoparticles, we coated macrophage cell membranes (MPCMs) around the 79 nanoparticles, whose surface biomacromolecules can actively recruit to tumour tissues 80 and increase retention and accumulation because of their ability to recognize tumour 81 cells and respond to tumour region signal molecules.(19-21). 
82 Considering the interrelationship between the TME and tumour therapy, we proposed

83 a treatment strategy with a MOF as the framework, PPy as the core, CTD as the model

84 drug, loading with a large amount of $\mathrm{Fe}^{3+}$, and MPCM as the outer coating. This strategy

85 has the following behaviours: 1) MPCM can give active targeting to nanoparticles(22,

86 23), and escape the immune clearance of macrophages to obtain long-lasting 87 circulation(24). 2) After reaching the tumour, a laser can be used to irradiate the tumour.

88 At this time, the photothermal agent reacts. Under the catalysis of heat, the coated 89 MPCM ruptures and the PCM releases CTD and iron ions. 3) CTD is used for tumour 90 treatment as a chemotherapeutic agent and inhibition of the HSR in tumour cells. 4) In

91 GSH overexpressed tumour tissues, $\mathrm{Fe}^{3+}$ is reduced to $\mathrm{Fe}^{2+}$, which mediates the down92 regulation of GPX4 and leads to ferroptosis(25). 5) Under high temperature, $\mathrm{Fe}^{2+}$ 93 undergoes a strong Fenton reaction with $\mathrm{H}_{2} \mathrm{O}_{2}$ in the TME to generate hydroxyl free 94 radicals that kill tumour cells. $\mathrm{Fe}^{2+}$ can also generate oxygen to improve the anoxic $95 \operatorname{TME}(26,27)$, downregulate HIF-1 $\alpha$ and inhibit tumour expansion. This strategy 96 worked well in both cellular and mouse models, indicating that it is a very effective 97 tumour treatment strategy. 

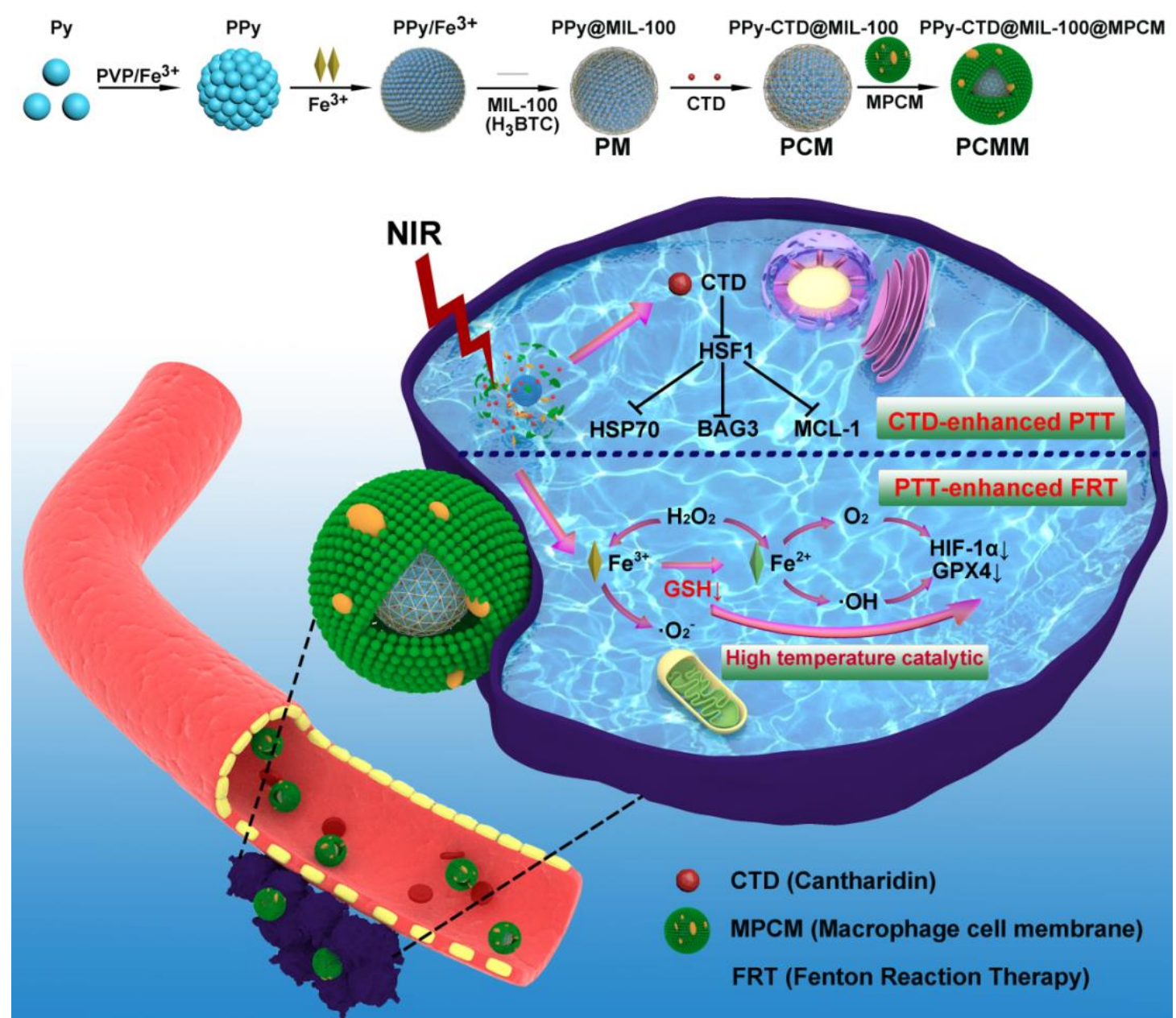

99 Scheme 1. Schematic illustration of the preparation of PCMM NPs and cantharidin-

100 loaded biomimetic MOF nanoparticles cascade to enhance Fenton reaction based on

101 amplified photothermal therapy.

\section{Materials and methods}

\subsection{Materials}

104 Polyvinylpyrrolidone (PVP, K30, MW $\approx 45000-58000$ ), pyrrole (Py), $\mathrm{FeCl}_{3} \cdot 6 \mathrm{H}_{2} \mathrm{O}$

105 (97\%), CTD, 1,3,5-Benzenetricarboxylic acid ( $\left.\mathrm{H}_{3} \mathrm{BTC}\right)$, doxorubicin hydrochloride

106 (DOX), DMPO (5,5-dimethyl-1-pyrroline N-oxide), Rhd B (Rhodamine B) and Phe

107 (1,10-phenanthroline monohydrate) were obtained from Aladdin (Shanghai, China). 
108 Phenylmethylsulfonyl fluoride (PMSF) was obtained from Macklin (Shanghai, China).

109 4',6-Diamidino-2-phenylindole (DAPI) was obtained from Solarbio (Beijing, China).

110 A Calcein-AM/PI Double Stain Kit was provided by Yeasen (Shanghai, China). An

111 Annexin V-FITC/PI Cell Apoptosis Kit, DCFH-DA and a Cell Counting Kit-8 (CCK-

112 8) were purchased from APExBIO. Foetal bovine serum (FBS), RPMI-1640 Medium

113 Modified, Dulbecco's Modified Eagle's Medium (DMEM), trypsin-EDTA and

114 penicillin-streptomycin were obtained from HyClone. RIPA lysis buffer and BCA

115 assay kits were purchased from Solarbio (Beijing, China). Protease inhibitor cocktail

116 (EDTA-Free, 100x in DMSO) was purchased from APExBIO. All antibodies were

117 obtained from Abcam.

\subsection{Preparation of PCMM}

\subsubsection{Synthesis of PM (PPy@MIL-100)}

120 The process of PM synthesis has improved from previously reports(28, 29). $1 \mathrm{~g}$ of PVP

121 was completely dissolved in $25 \mathrm{~mL}$ of deionized water and stirred for $30 \mathrm{~min}$, and 2

$122 \mathrm{mM}$ of pyrrole was added to the PVP solution and stirred for $10 \mathrm{~min}$. Next, $3 \mathrm{mM}(1$

$123 \mathrm{~mL}) \mathrm{FeCl}_{3} \cdot 6 \mathrm{H}_{2} \mathrm{O}$ solution was added to the mixed solution, and stirring was continued

124 for $4 \mathrm{~h}$. A volume of $600 \mu \mathrm{L}$ of PPy NPs was placed into $10 \mathrm{~mL}$ of ethanol solution and

125 stirred in a water bath at $75{ }^{\circ} \mathrm{C}$. Subsequently, $1 \mathrm{mM}(1 \mathrm{~mL})$ of $\mathrm{H}_{3} \mathrm{BTC}$ solution was

126 added to the mixed solution, and stirring was continued for 30 min to obtain a

127 framework structure before washing several times with deionized water to remove 128 excess ions and obtain PM. 


\subsubsection{Preparation of PCM (PPy-CTD@MIL-100)}

$130 \mathrm{CTD} 100 \mu \mathrm{L} / \mathrm{mL}$ was prepared. PM $(1 \mathrm{~g} / \mathrm{mL})$ was dissolved in $1 \mathrm{~mL}$ of ethanol, and 1

$131 \mathrm{~mL}$ of $100 \mu \mathrm{L} / \mathrm{mL}$ CTD was added and stirred for $24 \mathrm{~h}$. PCM was obtained by

132 centrifugation, and $100 \mu \mathrm{L}$ of supernatant was collected. The absorbance value at 228

$133 \mathrm{~nm}$ was detected, and the drug loading was determined.

134

135

136

137

\subsubsection{Preparation of MPCM}

MPCM was extracted according to previous reports(24). After medium removal and two washes with PBS, RAW264.7 cells were collected in a centrifuge tube. $10 \mathrm{~mL}$ of $\mathrm{NaHCO}_{3}(1 \mathrm{mmol} / \mathrm{L}), 0.05 \%$ Trypsin-EDTA $(0.2 \mathrm{mmol} / \mathrm{L})$ and PMSF $(1 \mathrm{mmol} / \mathrm{L})$ were added overnight. After crushing 10 times, the pellet was centrifuged at $3200 \mathrm{~g}$ for $5 \mathrm{~min}$, and the supernatant was centrifuged at $1 \times 10^{5} \mathrm{~g}$ for $30 \mathrm{~min}$. PBS was added for resuspension.

\subsubsection{Preparation of PCMM (PPy-CTD@MIL-100@MPCM)}

The equal volume of $2 \mathrm{mg} / \mathrm{mL}$ MPCM and PCM were mixed, and the above mixed solution was extruded through $200 \mathrm{~nm}$ polycarbonate membrane by a micro extruder for no less than 11 times. Finally, PCMM NPs was obtained.

\subsection{Characterization}

Transmission electron microscopy (TEM) (FEI Tecnai G2 F30) was used to characterize the morphology of the nanoparticles. Dynamic light scattering (DLS) analysis using a Malvern Zeta sizer Nano ZS (Malvern, UK) was conducted to measure 
150 (Thermo Scientific Instrument Co., Ltd.) was used to measure the optical absorbance.

151 An electronic paramagnetic resonance apparatus (Bruker, Germany) was used to

152 identify the types of ROS. An NIR laser with a centre wavelength of $808 \mathrm{~nm}$ was used

153 for irradiation (Changchun New Industries Optoelectronics Tech. Co., Ltd.). A

154 PerkinElmer in vivo imager was used to record the drug distribution in vivo.

\subsection{The ability of PCM to generate ROS and the ability to reduce GSH}

156 In order to ignore the influence of macrophage membrane on the reaction, we observed

157 the changes at $650 \mathrm{~nm}$ to evaluate the amount of $\cdot \mathrm{OH}$ produced by the Fenton reaction

158 between $\mathrm{TMB}$ and $\mathrm{PCM}$ at different temperatures $\left(25^{\circ} \mathrm{C}\right.$ and $\left.47^{\circ} \mathrm{C}\right)$. Additionally,

159 more accurate DMPO was used as a capture agent, and electron paramagnetic resonance

160 was used to determine the type of ROS generated. A reducing GSH Kit and Phe were

161 used to measure the ability of PCM to reduce GSH at different temperatures $\left(25^{\circ} \mathrm{C}\right.$ and

$16247^{\circ} \mathrm{C}$ ). The change in absorbance at $425 \mathrm{~nm}$ was used to monitor PCMM NPs (75

$163 \mu \mathrm{g} / \mathrm{mL})$ containing $\mathrm{H}_{2} \mathrm{O}_{2}$ in the presence/absence of $\mathrm{GSH}(1 \mathrm{mM})$. By detecting the

164 change in absorbance at $525 \mathrm{~nm}$, the GSH consumption capacity of $\mathrm{Fe}^{3+}$ in PCMM NPs

165 (0.2 mM Phe, $75 \mu \mathrm{g} / \mathrm{mL}$ PCMM NPs) containing $\mathrm{H}_{2} \mathrm{O}_{2}$ was observed in the presence 166 or absence of $10 \mathrm{mM} \mathrm{GSH}$.

\subsection{PCMM thermal performance}

168 To further study the photothermal performance of PCMM NPs, we explored the

169 photothermal performance of different light intensights $\left(500,750\right.$ and $\left.1000 \mathrm{~mW} / \mathrm{cm}^{2}\right)$ 
and different drug concentrations $(0,25,50$ and $75 \mu \mathrm{g} / \mathrm{mL}$, using DMEM complete

171 medium to prepare different concentrations). The photothermal effect was studied

172 under a simulated human body temperature environment $\left(37^{\circ} \mathrm{C}\right)$. One millilitre of

173 PCMM NPs at different concentrations was placed in a $37{ }^{\circ} \mathrm{C}$ environment, $808 \mathrm{~nm}$

174 near-infrared lasers with different light intensities provided irradiation for $10 \mathrm{~min}$, and

175 the temperature was recorded every $30 \mathrm{~s}$ using a digital thermocouple device. To

176 observe the thermal performance of PCMM NPs more intuitively, an infrared thermal

177 imager (FLIR, USA) was used to capture infrared thermal images of the suspension of

178 PCMM NPs every 2 min. To calculate the photothermal conversion efficiency $(\eta)$ of

179 PCMM NPs, a suspension of PCMM NPs $(75 \mu \mathrm{g} / \mathrm{mL}, 1.0 \mathrm{~mL})$ and deionized water (1.0

$180 \mathrm{~mL})$ was treated with an NIR laser $\left(1 \mathrm{~W} / \mathrm{cm}^{2}\right)$ for $20 \mathrm{~min}$. After the laser was turned off,

181 the suspension was naturally cooled to ambient temperature. The temperature of the

182 solution was measured every $30 \mathrm{~s}$, and a temperature graph was drawn. To an amount

183 of $75 \mu \mathrm{g} / \mathrm{mL}$ of PCMM NPs at $37^{\circ} \mathrm{C}, 1000 \mathrm{~mW} / \mathrm{cm}^{2}$ was applied with a $808 \mathrm{~nm}$ near-

184 infrared laser for $10 \mathrm{~min}$, and after the laser was turned off, the solution was cooled to

$18537{ }^{\circ} \mathrm{C}$. This process was repeated five times. The light resistance of the nanoparticles

186 was tested by recording the temperature of the solution. To measure the photothermal

187 conversion efficiency, PCMM NPs $(75 \mu \mathrm{g} / \mathrm{mL}, 1.0 \mathrm{~mL})$ and deionized water $(1.0 \mathrm{~mL})$

188 were irradiated with a NIR laser $\left(1 \mathrm{~W} / \mathrm{cm}^{2}\right)$ for $20 \mathrm{~min}$. After the laser was turned off,

189 the suspension was naturally cooled to ambient temperature. The temperature of the

190 solution was measured every $30 \mathrm{~s}$, and a temperature graph was drawn. 


\subsection{In vitro drug release}

192 A dialysis method was used to study the release behaviour of CTD in PCMM NPs after 0,500, 750 and $1000 \mathrm{~mW} / \mathrm{cm}^{2}$ laser irradiation. In short, PCMM NPs $(1 \mathrm{mg} / \mathrm{mL})$ were

194 dissolved in $1 \mathrm{~mL}$ of PBS (pH 7.4), and the mixture was placed in a dialysis bag (MW

$195=14000)$. The dialysis bag was placed in PBS buffer $(70 \mathrm{~mL})$ and shaken horizontally

196 (80 rpm) in a shaker at $37^{\circ} \mathrm{C}$ to release the medium. At predetermined time points $(0$,

$1972,4,6,8,12,24$ and $48 \mathrm{~h}), 100 \mu \mathrm{L}$ of the solution was removed from the buffer medium,

198 and the amount of CTD released was measured using a UV-Vis spectrophotometer.

\subsection{Cell culture}

All cell lines used in this study were purchased from Procell Biotech (Wuhan, China).

201 Human liver cancer cells (HepG2), mouse mononuclear macrophage leukaemia cells 202 (RAW 264.7), human embryonic kidney cells (293T) and mouse liver cancer cells 203 (HepA1-6) were maintained in $10 \%$ FBS, $100 \mu \mathrm{g} / \mathrm{mL}$ penicillin and $100 \mathrm{mg} / \mathrm{mL}$ 204 streptomycin in complete DMEM. Mouse liver cancer cells (H22) were cultured in 205 complete 1640 medium. All of the above cell lines were cultured at $37{ }^{\circ} \mathrm{C}$ in a humid 206 environment containing $5 \% \mathrm{CO}_{2}$.

\section{$207 \quad 2.8$ In vitro safety analysis}

208 Blood from BALB/c mice was used to analyse the biocompatibility of PM, PCM and 209 PCMM. Whole blood was collected from mice via retro-orbital bleeding, and then it 210 was added to an EDTA anticoagulation tube and shaken evenly. The blood was 
211 centrifuged at $1500 \mathrm{rpm}$ at $4{ }^{\circ} \mathrm{C}$ for 5 min and washed 3 times with PBS. An amount of

$21220 \mu \mathrm{L}$ of red blood cell suspension was added to various concentrations of PM, PCM

213 and PCMM in PBS suspension $(25,50$ and $75 \mu \mathrm{g} / \mathrm{mL} ; 1.0 \mathrm{~mL})$. After shaking at $37^{\circ} \mathrm{C}$

214 for $4 \mathrm{~h}$ in a shaker at a speed of $100 \mathrm{r} / \mathrm{min}$, images were captured. Finally, $100 \mu \mathrm{L}$ of

215 supernatant was removed from each experimental group, and the absorbance was

216 measured at $540 \mathrm{~nm}$ using a microplate reader. Deionized water and PBS (pH 7.4) were

217 used as positive and negative controls, respectively. The haemolysis rate was calculated

218 using the following formula:

$$
\text { Haemolysis }(\%)=\left(A_{\text {Sample }}-A_{\text {Negative }}\right) /\left(A_{\text {Positive }}-A_{\text {Negative }}\right) \times 100 \%
$$

The viability of cells in PM, PCM and PCMM at different drug concentrations $(0,25$,

22150 and $75 \mu \mathrm{g} / \mathrm{mL})$ was tested using a CCK-8. HepG2 and 293T cells $\left(5 \times 10^{4} / 100 \mu \mathrm{L}\right)$

222 were seeded in 96-well plates and incubated overnight to allow them to attach to the

223 bottom. Different concentrations of PM, PCM, and PCMM were incubated with HepG2

224 and $293 \mathrm{~T}$ cells for $48 \mathrm{~h}$. An amount of $10 \mu \mathrm{L}$ CCK-8 was added to each well, and the 225 absorbance at $450 \mathrm{~nm}$ was detected.

\subsection{Cellular uptake assay}

227 The uptake of PM, PCM, and PCMM by a variety of cells (RAW264.7, 293T, HepG2

228 and HepA1-6) was evaluated by CLSM and flow cytometry. The autofluorescence of 229 DOX (adriamycin) was used instead of CTD to detect the uptake ability, so we prepared 230 PDM (PPy-DOX@MIL-100) and PDMM (PPy-DOX@MIL-100@MPCM). To 231 directly observe the uptake capacity, four types of cells $\left(1 \times 10^{4}, 500 \mu \mathrm{L}\right)$ were cultured 232 on round slides and incubated with medium containing PDM and PDMM. After the 
233 proper incubation time, the round glass slides were washed with PBS 3 times and fixed 234 with $4 \%$ paraformaldehyde for $15 \mathrm{~min}$. The nucleus were stained with DAPI $(5 \mu \mathrm{g} / \mathrm{mL})$ 235 for $15 \mathrm{~min}$ and washed twice with PBS. Finally, the cells were imaged by CLSM. To 236 determine the cell uptake ratio, RAW264.7, 293T, HepG2 and HepA1-6 cells were 237 inoculated in 24-well plates and cultured overnight. The cells were incubated with 50 $238 \mu \mathrm{g} / \mathrm{mL}$ PDM and PDMM $\left(15 \mu \mathrm{g} / \mathrm{mL}\right.$ DOX) at $37{ }^{\circ} \mathrm{C}$ for $2 \mathrm{~h}$, and the samples were 239 collected and analysed by flow cytometry.

\subsection{Generation and determination of ROS}

241 A DCFH-DA reactive oxygen analysis kit was used to evaluate the ROS generation 242 ability of the nanoparticles. HepG2 cells were seeded in 24 -well plates $\left(5 \times 10^{5}\right.$ cells/well $)$ 243 and incubated overnight. On the next day, the medium was removed, $\operatorname{PCMM}(0,25,50$ 244 and $75 \mu \mathrm{g} / \mathrm{mL}$ ) containing $\mathrm{H}_{2} \mathrm{O}_{2}$ was added to the medium, and laser (808 nm; 0, 500, 245750 and $1000 \mathrm{~mW} / \mathrm{cm}^{2} ; 10 \mathrm{~min}$ ) treatment was applied. The cells were washed and 246 treated with serum-free medium containing DCFH-DA $(10 \mu \mathrm{M})$ for $20 \mathrm{~min}$. 247 Subsequently, the cells were again washed 3 times with serum-free medium. Finally, 248 the generation of ROS was observed using confocal laser scanning microscopy (CLSM, 249 Heidelberg, Germany).

\subsection{In vitro cytotoxicity of single PTT and combination therapy}

251 The effects of single PTT and combination therapy were evaluated by AM-PI double 252 staining experiments, flow cytometry and CCK-8 assays. For qualitative analysis, 253 HepG2 cells were seeded in 96-well plates overnight. Under the premise of controlling 
254 a single variable, $\operatorname{PCMM}(0,25,50$ and $75 \mu \mathrm{g} / \mathrm{mL})$ was added and incubated for $6 \mathrm{~h}$ in 255 the presence or absence of $\mathrm{H}_{2} \mathrm{O}_{2}$. After treatment with a NIR laser $(808 \mathrm{~nm}, 0,500,750$ 256 and $\left.1000 \mathrm{~mW} / \mathrm{cm}^{2} ; 10 \mathrm{~min}\right)$, the cells were placed in an incubator and incubated for 4

257 h. Live cells and dead cells were stained with calcein-acetoxymethyl ester (calcein-AM) 258 and propidium iodide (PI), and fluorescent images were captured with an inverted 259 fluorescence microscope (Leica DMI4000B) for qualitative analysis. The quantitative 260 cytotoxicity results were obtained using flow cytometry. Similar to CLSM, after 261 staining of live and dead cells with Annexin V FITC and PI, respectively, quantitative 262 analysis was performed by flow cytometry. After treatment with the same treatment 263 conditions again, $10 \mu \mathrm{L}$ of CCK-8 was added to each well and incubated for another 1 $264 \mathrm{~h}$ at $37{ }^{\circ} \mathrm{C}$. Finally, a microplate reader (BioTek, USA) was used to measure the 265 absorbance of each well at $450 \mathrm{~nm}$ to quantify the cytotoxicity of PCMM.

\subsection{Exploration of the inhibitory effect of PCMM NPs on HSR}

267 To explore the inhibitory effect of PCMM NPs on the HSR under a single photothermal 268 treatment, we conducted western blotting. HepG2 cells were incubated with PCMM 269 NPs of different concentrations $(0,25,50$ and $75 \mu \mathrm{g} / \mathrm{mL})$ for $6 \mathrm{~h}$, irradiated at $37{ }^{\circ} \mathrm{C}$ 270 with a NIR laser with different light intensities $\left(808 \mathrm{~nm} ; 0,500,750\right.$ and $1000 \mathrm{~mW} / \mathrm{cm}^{2}$; $27110 \mathrm{~min}$ ), the protein was extracted after $12 \mathrm{~h}$ of incubation. HSF1 downstream target 272 proteins (HSP70, BAG3 (Bcl-2 associated oncogene domain 3) and MCL-1) were used 273 to evaluate the expression levels of heat shock proteins (HSPs). 
Based on the above experimental results, we screened the optimal conditions for in vivo experiments. A tumour-bearing animal model was established for female BALB/c mice

277 (6 weeks old, Liaoning Changsheng Biotechnology Co., Ltd.). H22 cells $\left(1 \times 10^{6}\right.$, 278 suspended in $100 \mu \mathrm{L}$ PBS) were injected subcutaneously into the right armpit of each 279 mouse, and the tumour volume was measured one week later. When the tumour size 280 reached $50 \mathrm{~mm}^{3}$, the mice were further used for in vivo experiments. All animal 281 procedures in this investigation were approved by the Institutional Animal Care and 282 Use Committee of Dalian University of Technology.

283 The tumour volume is defined as $\mathrm{V}=\mathrm{W}^{2} \mathrm{~L} / 2$, where $\mathrm{W}$ and $\mathrm{L}$ represent the shorter and 284 longer diameters of the tumour, respectively.

\subsection{Drug distribution in the body}

PCMM-Rhd B and PCM-Rhd B were prepared. PCMM and PCM were mixed with Rhd

287 B in equal proportions and centrifuged to obtain PCMM-Rhd B and PCM-Rhd B. PCMM-Rhd B and PCM-Rhd B were injected into shaved BALB/c mice with tumours up to $1000 \mathrm{~mm}^{3}$. A PerkinElmer in vivo imager was used to record the drug distribution in vivo at $0 \mathrm{~h}, 0.5 \mathrm{~h}, 2 \mathrm{~h}, 6 \mathrm{~h}, 12 \mathrm{~h}, 24 \mathrm{~h}, 48 \mathrm{~h}$ and $72 \mathrm{~h}$.

\subsection{In vivo drug efficacy evaluation}

292 The tumour-bearing mice were randomly divided into eight groups ( $\mathrm{n}=4)$ : (1) PBS, (2) PBS+1000 mW/cm², (3) PMM, (4) PMM+1000 mW/cm², (5) PCMM, (6) PCMM+500

$294 \mathrm{~mW} / \mathrm{cm}^{2}$, (7) PCMM+750 $\mathrm{mW} / \mathrm{cm}^{2}$ and (8) PCMM+1000 $\mathrm{mW} / \mathrm{cm}^{2}$. Each group of 295 mice was injected intravenously with $5 \mathrm{mg} / \mathrm{kg}$ PBS, PMM or PCMM $(0.1 \mathrm{mg} / \mathrm{kg} \mathrm{CTD}$, 

with an NIR laser (808 nm, $10 \mathrm{~min}) 12 \mathrm{~h}$ after administration. Every two days after

298 treatment, the tumour size and weight of each mouse were measured with digital 299 calipers and an electronic balance. After 15 days of treatment, blood was collected from 300 all mice for routine blood analysis. Finally, the mice were sacrificed and dissected. The 301 tumour was removed, weighed and photographed. The main organs (heart, liver, spleen, 302 lung, kidney) and tumour of the mice were fixed in $10 \%$ formalin. $5 \mu \mathrm{m}$ paraffin 303 sections were prepared. After deparaffinization in xylene and dehydration in a graded 304 series of alcohols, haematoxylin and eosin (H\&E) was used to stain the organ-loaded 305 slides. The nucleus was stained blue, and the cytoplasm was stained red. The cells were 306 observed using an optical microscope.

\section{$307 \quad 2.16$ Immunofluorescence}

308 To study the therapeutic mechanism of PCMM NPs, we performed

309 immunofluorescence staining on tumour tissue sections. The treated mice were 310 sacrificed, and tumour sections were taken and fixed for staining. To assess the activity 311 of GPX4, anti-rabbit GPX4 and Alexa Fluor 488® secondary antibodies were used for 312 immunofluorescence staining. Anti-mouse HIF-1 $\alpha$ and Alexa Fluor 594® secondary 313 antibodies were used to evaluate the expression of HIF-1 $\alpha$. 


\subsection{Statistical analysis}

315 All experiments were repeated at least 3 times, and all results are expressed as the mean \pm SD. A two-tailed heteroscedasticity Student's t-test was used to evaluate

317 statistical significance $(*, \mathrm{P}<0.05 ; * *, \mathrm{P}<0.01$; and $* * *, \mathrm{P}<0.001)$.

\section{Results and discussion}

\subsection{Preparation and characterization of PCMM}

The preparation of PCMM includes four steps. First, PPy NPs were polymerized at

321 room temperature. The TEM image shows that PPy NPs are spherical particles with an 322 average diameter of about $40 \mathrm{~nm}$ (Fig. 1a). PM NPs were obtained at a high temperature

323 of $75^{\circ} \mathrm{C}$. The TEM image shows that PM NPs have a spherical structure with an 324 average diameter of about $80 \mathrm{~nm}$ (Fig. 1b). As shown in Fig. S1, the DLS image shows 325 that the average hydrodynamic diameters of PPy and PM are $68.1 \mathrm{~nm}$ and $106 \mathrm{~nm}$, 326 respectively. The mapping image clearly shows the elemental distribution of PM NPs. 327 It is clear that iron is abundantly distributed in PM NPs (Fig. 1cdef). Next, the obtained 328 PM NPs were mixed with the CTD solution and stirred for $24 \mathrm{~h}$ to obtain the PCM NPs.

329 The absorbance of the supernatant was measured, and the loading efficiency of CTD 330 was approximately $29.02 \%$. Finally, the cell membrane was extracted from RAW264.7 331 cells by differential centrifugation. The resulting mixture was passed through a $200 \mathrm{~nm}$ 332 polycarbonate membrane no less than 11 times to obtain PCMM NPs camouflaged by

333 MPCM. The TEM image clearly shows that the PCM NP is completely wrapped by the 334 phospholipid bilayer (Fig. 1g). As shown in the UV-Vis-NIR absorption spectrum (Fig. 
335 1h), the characteristic peaks $(260 \mathrm{~nm})$ of cell membranes were also found in PCMM

336 NPs. As shown in Fig. 1i, the DLS image shows that the average hydrodynamic 337 diameter of the NPs after coating is about $200 \mathrm{~nm}$. The above results indicate that PCM 338 NPs were successfully encapsulated by MPCM.

\section{$339 \quad 3.2$ Ability of PCM to generate ROS and reduce GSH}

340 To confirm that PCM NPs can produce ROS in the presence of $\mathrm{H}_{2} \mathrm{O}_{2}$, TMB was used 341 to evaluate the efficiency of peroxidase. As shown in Fig. 1j, by comparing the 342 absorption value at $650 \mathrm{~nm}$, it is obvious that PCM can indeed consume $\mathrm{H}_{2} \mathrm{O}_{2}$ in the 343 presence of $\mathrm{H}_{2} \mathrm{O}_{2}$. As shown in Fig. $1 \mathrm{k}$ and 1, by comparing the absorption values of $344 \mathrm{PCM} / \mathrm{H}_{2} \mathrm{O}_{2}\left(25^{\circ} \mathrm{C}\right)$ and $\mathrm{PCM} / \mathrm{H}_{2} \mathrm{O}_{2}\left(47^{\circ} \mathrm{C}\right)$ at $650 \mathrm{~nm}$, it can be observed that increasing 345 the reaction temperature can indeed increase this peroxidase-like activity. As an 346 important intracellular antioxidant, GSH plays an irreplaceable role in protecting cells 347 against increased intracellular oxidative stress(30). Therefore, we hypothesize that $\mathrm{Fe}^{3+}$ 348 can be reduced to $\mathrm{Fe}^{2+}$ by GSH and that $\mathrm{Fe}^{2+}$ can form a citrinine complex with 1,10 349 phenanthroline monohydrate (Phe). As shown in Fig. 1m, the absorption peak at 525 $350 \mathrm{~nm}$ in the $\mathrm{UV}$-Vis absorption spectrum indicate that $\mathrm{Fe}^{3+}$ in PCMM does have the ability 351 to consume GSH. Fig. 1n also suggests that high temperature can improve this ability. 352 To analyse the types of ROS generated, 5,5-dimethyl-1-pyrroline-N-oxide (DMPO) 353 was used as an electron paramagnetic resonance capture probe. As shown in Fig. 1o, $354 \mathrm{PCM}$ and $\mathrm{H}_{2} \mathrm{O}_{2}$ alone cannot produce obvious characteristic spectra at room 355 temperature. At $47^{\circ} \mathrm{C}$, in the presence of $\mathrm{GSH}, \mathrm{PCM} / \mathrm{H}_{2} \mathrm{O}_{2}$ induced the generation of a 

generation efficiency of the ROS increases at high temperature.
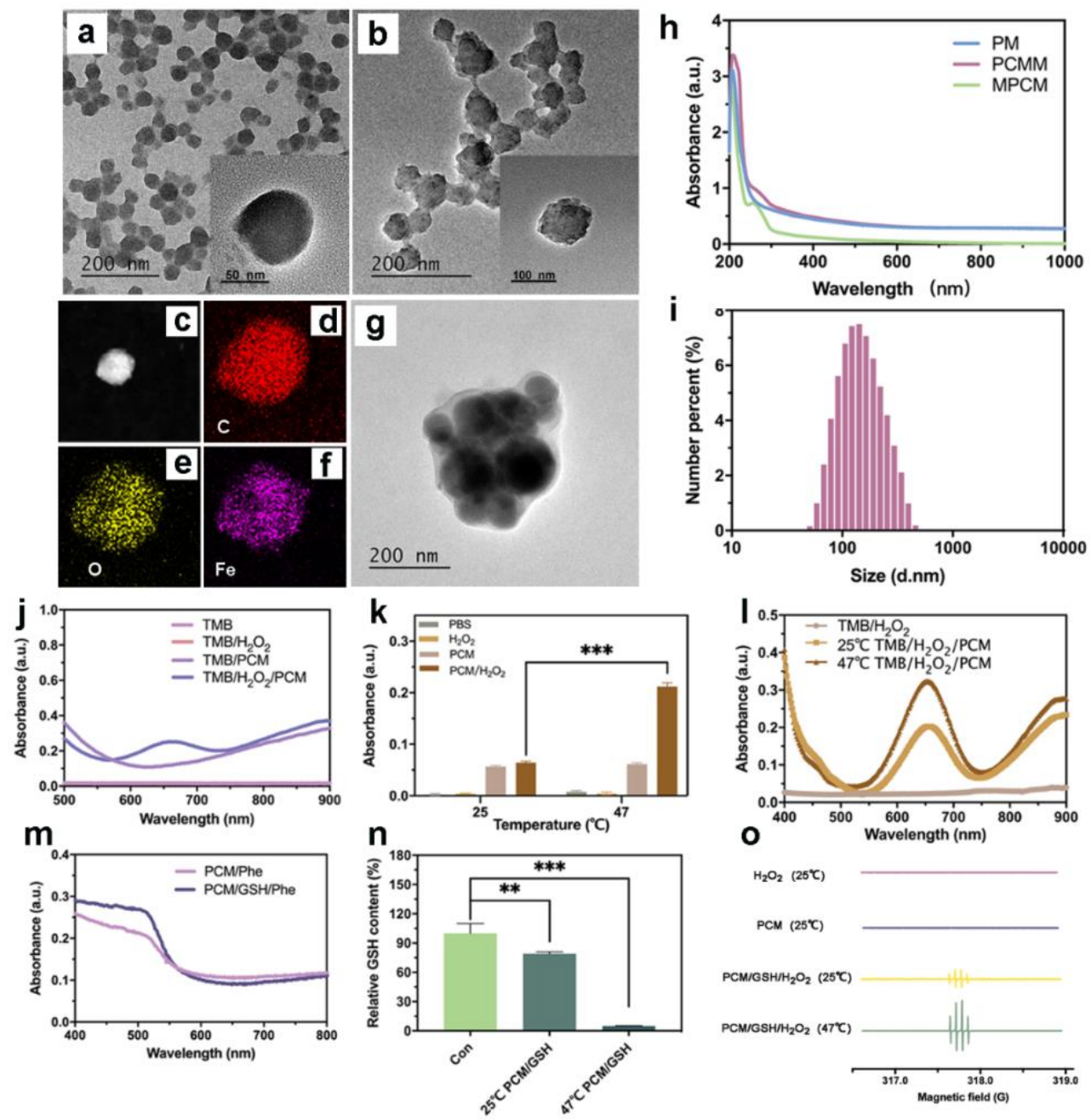

$$
0
$$

$\mathrm{H}_{2} \mathrm{O}_{2}\left(25 \mathrm{C}^{\circ}\right)$

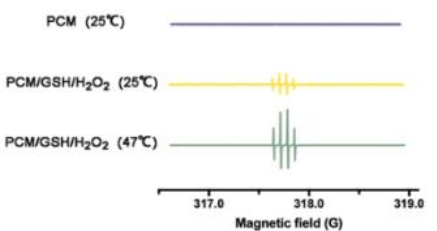

360 Fig. 1. a) TEM image of PPy NPs. b) TEM image of PM and c) corresponding dark

361 field TEM image and element mapping of d) carbon $(\mathrm{C}$, red), e) oxygen (O, yellow)

362 and f) iron (Fe, purple) in the selected area. g) TEM image of PCMM. h) UV-Vis

363 absorption spectra of PM, MPCM and PCMM. i) Average hydrodynamic size of

364 PCMM. j) UV-Vis absorption spectra of TMB solutions treated with different groups.

$365 \mathrm{k})$ Absorbance of $\mathrm{TMB}$ at $650 \mathrm{~nm}$ after incubation for $5 \mathrm{~min}$ under the specified 
conditions. 1) UV-Vis absorption spectra of TMB and $\mathrm{H}_{2} \mathrm{O}_{2}$ incubated with PCM at

different temperatures. m) UV-Vis absorption spectra of the PCM/Phe and

PCM/GSH/Phe groups. n) Evaluation of the GSH consumption capacity of PCM NPs at different temperatures with the GSH Kit. o) EPR spectrum of PCM with DMPO as the capture agent under specified conditions. *, $\mathrm{P}<0.05$; **, $\mathrm{P}<0.01$; ***, $\mathrm{P}<0.001$.

\subsection{Photothermal performance of PCMM NPs}

To determine the photothermal performance of PCMM NPs, photothermal conversion experiments were conducted. The suspensions of PCMM NPs with gradient concentrations $(25,50$ and $75 \mu \mathrm{g} / \mathrm{mL})$ were exposed to an $808 \mathrm{~nm}$ laser, and each concentration of the PCMM NPs was exposed to three light intensities (500, 750 and $1000 \mathrm{~mW} / \mathrm{cm}^{2}$ ) for $10 \mathrm{~min}$. DMEM complete medium was used as a control group. As 377 shown in Fig. 2c and S2ab, the temperature of the PCMM suspension shows a clear 378 concentration-dependent increase over time. As shown in Fig. 2d and S3ab, the 379 temperature of the PCMM suspension shows a clear light intensity-dependent increase 380 over time. In a $37^{\circ} \mathrm{C}$ environment, after $1000 \mathrm{~mW} / \mathrm{cm}^{2}$ laser irradiation, the maximum 381 temperature $\left(T_{\max }\right)$ of PCMM NPs with a concentration of $75 \mu \mathrm{g} / \mathrm{mL}$ quickly reached $38255.9^{\circ} \mathrm{C}$ while the $T_{\max }$ of DMEM only increased to $38.8^{\circ} \mathrm{C}$ under the same conditions.

383 Due to the satisfactory photothermal conversion characteristics, PCMM NPs also 384 provide high contrast in infrared thermal imaging (Fig. 2ab, S2cd and S3cd). The 385 infrared thermal imaging mode can be used to identify the location of the PTT agent 386 and provide real-time monitoring of the PTT treatment effect. The photothermal 

reported in the literature(31). Based on the obtained data shown in Fig. 2e, the following

389 formula was used to calculate the $\eta$ of PCMM NPs:

$$
\eta=\frac{h S\left(T_{\max }-T_{\text {max }, \text { water }}\right)}{I\left(1-10^{\left.-A_{\lambda}\right)}\right.}
$$

391 where $h$ represents the heat transfer coefficient, $S$ is the area perpendicular to the cross392 section of the laser transmitter, $T_{\max }$ and $T_{\max \text {,water }}$ are the highest temperatures that the 393 nanoparticle sample solution and pure water can respectively reach after laser 394 irradiation, $I$ is the laser power, and $A_{\lambda}$ is the absorption value of a sample with a UV395 VIS-NIR spectrum of $808 \mathrm{~nm}$. The time constant ( $\tau s$ ) was determined from the cooling 396 cycle curve at 403.13 s (Fig. 2f), and the $\eta$ of PCMM was calculated as $39.92 \%$. 397 Compared with some excellent photothermal agents that have been reported, PCMM 398 still performs well $(32,33)$. The above results suggest that PCMM has strong potential 399 for PTT application. The photostability test of the PCMM was performed. After five 400 repeated heating cycles, the PCMM can still reach the efficiency of the first heating 401 cycle under light exposure (Fig. 2g). The above results suggest that the photothermal 402 effect of PCMM is comparable to that of other classic PTT reagent (such as Au NPs). 403 Drug release curve (Fig. 2h) showed that the average release rate of CTD within $48 \mathrm{~h}$ 404 without NIR laser irradiation was only $38.03 \%$, and the average release rate of CTD 405 within $48 \mathrm{~h}$ irradiated by $500 \mathrm{~mW} / \mathrm{cm}^{2}$ NIR laser irradiation was $53.09 \%$, while the 406 average release rate of CTD within $48 \mathrm{~h}$ irradiated by 750 and $1000 \mathrm{~mW} / \mathrm{cm}^{2} \mathrm{NIR}$ laser 407 irradiation was very similar, reaching more than $84 \%$. We hypothesize that this may be 

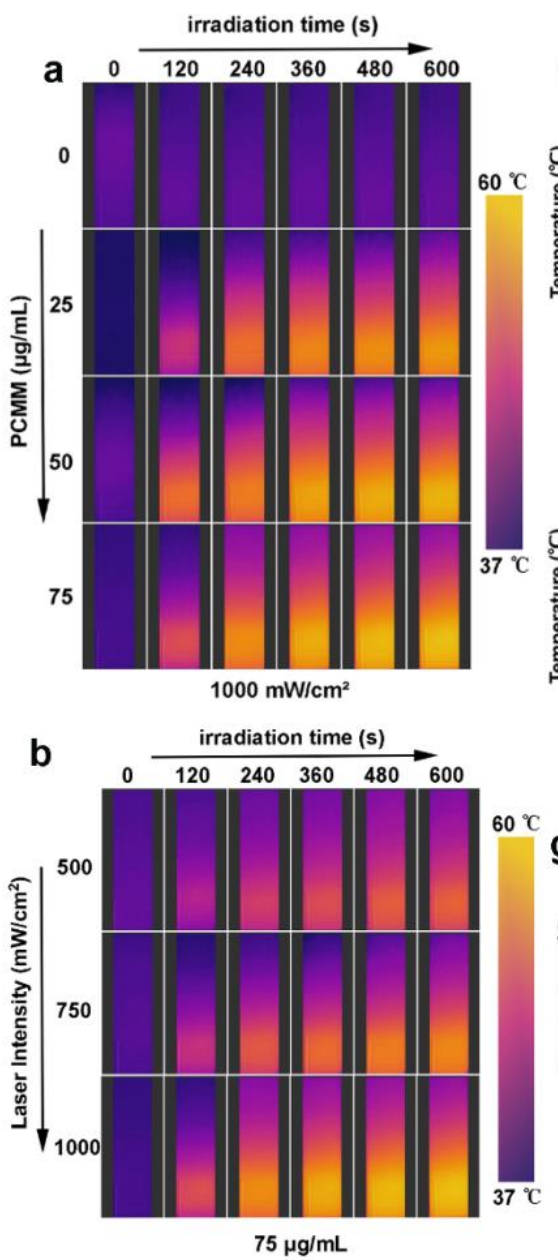

C

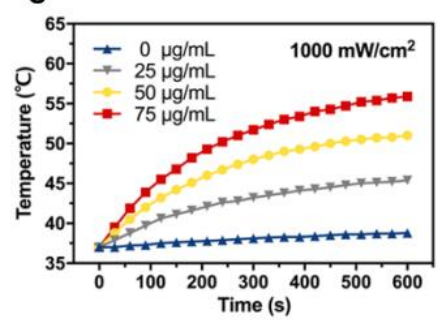

e
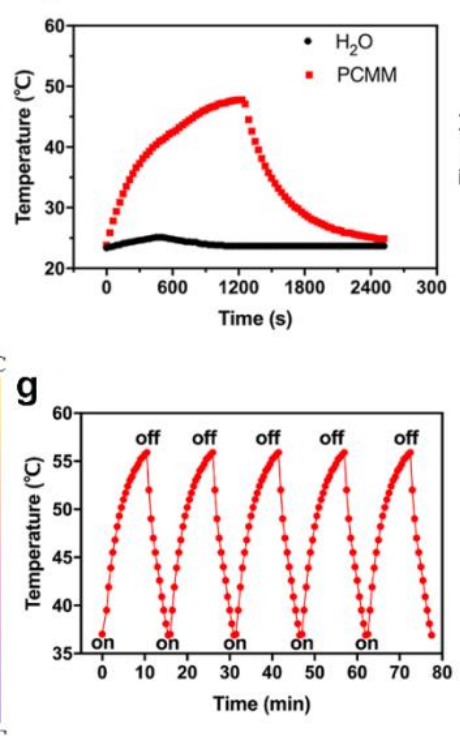

d

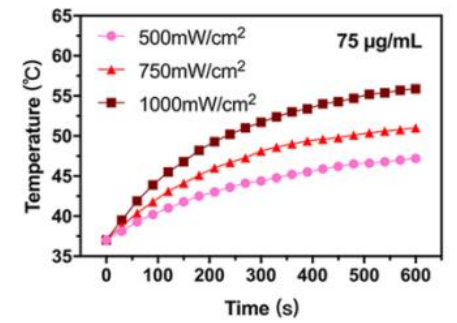

f

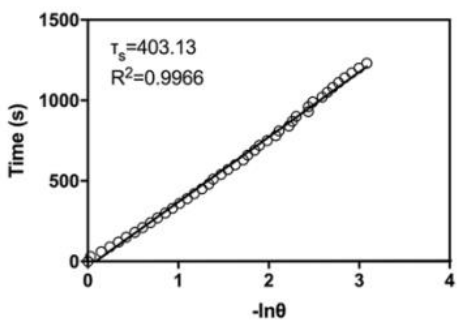

h

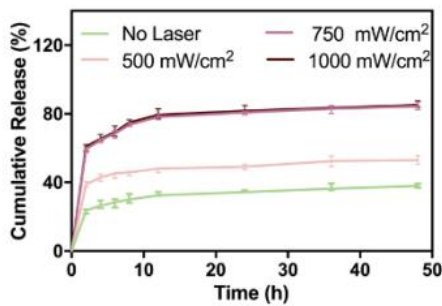

411 Fig. 2. Photothermal performance of PCMM in vitro. a) Near-infrared thermal images

412 of PCMM suspension at three concentrations with $1000 \mathrm{~mW} / \mathrm{cm}^{2}$ Near-infrared laser

413 irradiation $(808 \mathrm{~nm})$ for $10 \mathrm{~min}$ and b) Near-infrared thermal images of PCMM

414 suspension $(75 \mu \mathrm{g} / \mathrm{mL})$ with three light intensities of Near-infrared laser irradiation

$415(808 \mathrm{~nm})$ for 10 min. c) The temperature $\left({ }^{\circ} \mathrm{C}\right)$ of PCMM at $1000 \mathrm{~mW} / \mathrm{cm}^{2}$ Near-infrared 416 laser irradiation $(808 \mathrm{~nm})$ for $10 \mathrm{~min} . \mathrm{d})$ The temperature $\left({ }^{\circ} \mathrm{C}\right)$ of PCMM $(75 \mu \mathrm{g} / \mathrm{mL})$ 417 with three light intensities of Near-infrared laser irradiation (808 $\mathrm{nm}$ ) for $10 \mathrm{~min} . \mathrm{e})$ 
418 Heating and cooling curves of the PCMM suspension $(75 \mu \mathrm{g} / \mathrm{mL})$ and deionized water 419 at room temperature. f) The plot of cooling time versus negative natural logarithm of 420 the temperature driving force. g) Temperature change of the PCMM suspension (75 $421 \mu \mathrm{g} / \mathrm{mL}$ ) under laser irradiation for 5 on/off cycles. h) Drug release of PCMM with three 422 light intensities of Near-infrared laser irradiation $(808 \mathrm{~nm})$ for $10 \mathrm{~min}$. Unless otherwise 423 specified, the photothermal experiments were performed at $37^{\circ} \mathrm{C}$.

\subsection{Biocompatibility}

Biocompatibility is essential for nanomedicine used in cancer treatment. Therefore, we tested the hemolysis behaviour after incubation with red blood cells (RBCs) and the result showed negligible hemolysis (Fig. S4a). In addition, standard CCK-8 analysis was performed on HepG2 cells and $293 \mathrm{~T}$ cells to evaluate the biosafety of the nanoparticles. As shown in Fig. S4b and c, after $48 \mathrm{~h}$ of incubation with PM, PCM and $\operatorname{PCMM}(25,50$ and $75 \mu \mathrm{g} / \mathrm{mL})$, the cell viability was greater than $95 \%$. The above

431 results show that PCMM has good biocompatibility and blood compatibility.

\subsection{Cell uptake}

433 To evaluate the targeting ability of the coated MPCM, the uptake behaviour of PDM 434 and PDMM in RAW264.7, 293T, HepG2 and HepA1-6 cells was studied by CLSM 435 and flow cytometry. As shown in Fig. 3a, the CLSM results show that the cellular 436 uptake efficiency of PDMM in HepG2 and HepA1-6 cells is significantly higher than 437 that of PDM. This indicated that PCMM had higher selectivity to HepG2 and HepA14386 cells. The cellular uptake efficiency of PDMM in RAW264.7 and 293T cells is 
significantly lower than that of PDM. This may be due to the ability of MPCM's surface biomacromolecules to recognize tumour cells and respond to signal molecules in

441 tumour regions, so that MPCM can actively recruit to tumour tissues and increase 442 retention and accumulation. Flow cytometry (Fig. S5) and its quantitative results (Fig.

443 3b) showed that PDMM had a higher degree of internalization in HepG2 and HepA1-6 444 cells. The above results indicate that PDMM has a high active targeting ability against 445 tumour cells.

\subsection{Generation and determination of ROS}

As shown in Fig. 3c and S6, HepG2 cells treated with DMEM or PCM only generated a small amount of ROS under various light intensities. PCMM exhibited a ROS

449 generation level similar to that of DMEM without NIR irradiation. In the case of $450 \mathrm{PCMM} / \mathrm{H}_{2} \mathrm{O}_{2}$ at $25 \mu \mathrm{g} / \mathrm{mL}$, the ROS response was gradually emerging after irradiation 451 with light intensities of $500 \mathrm{~mW} / \mathrm{cm}^{2}$ and $750 \mathrm{~mW} / \mathrm{cm}^{2}$ for $10 \mathrm{~min}$. After irradiation 452 with light intensity of $1000 \mathrm{~mW} / \mathrm{cm}^{2}$ at $25 \mu \mathrm{g} / \mathrm{mL}$ of PCMM and $750 \mathrm{~mW} / \mathrm{cm}^{2}$ at 50 $453 \mu \mathrm{g} / \mathrm{mL}$ of PCMM for $10 \mathrm{~min}$, the generation level of ROS was greatly improved. We 454 speculate that the reason for this effect might be that the temperature increases in 455 response to the photothermal agent irradiated with the laser light, causing the MPCM 456 to rupture and a large amount of iron ions to be released.

\subsection{Cytotoxicity of PTT and combination therapy in vitro}

458 Encouraged by the effective photothermal conversion performance, ROS generation 459 ability and tumour cell-specific targeting characteristics, the in vitro antitumour ability 
of PCMM were further evaluated in CLSM, flow cytometry and CCK-8 analysis. We tested the PTT toxicity and combination therapy toxicity respectively. The cytotoxicity of PTT was obtained by formulating gradient concentrations of PCMM (25, 50 and 75 $\mu \mathrm{g} / \mathrm{mL}$ ) with cells and DMEM complete medium with or without $\mathrm{H}_{2} \mathrm{O}_{2}$ under different 464 light intensities $\left(500,750\right.$ and $\left.1000 \mathrm{~mW} / \mathrm{cm}^{2}\right)$ for $10 \mathrm{~min}$. As shown in Fig. S7, the 465 results of flow cytometry showed that the mortality rate reached more than $80 \%$ under 466 the conditions of $50 \mu \mathrm{g} / \mathrm{mL}$ and $1000 \mathrm{~mW} / \mathrm{cm}^{2}$ as well as $75 \mu \mathrm{g} / \mathrm{mL}$ and 750 and 1000 $467 \mathrm{~mW} / \mathrm{cm}^{2}$. Combination therapy was obtained by irradiating cells with $\mathrm{H}_{2} \mathrm{O}_{2}$-activated 468 PCMM (25, 50 and $75 \mu \mathrm{g} / \mathrm{mL})$ under different light intensities (500, 750 and 1000 $469 \mathrm{~mW} / \mathrm{cm}^{2}$ ) for $10 \mathrm{~min}$. As shown in Fig. 3d, the CLSM results showed that at a 470 concentration of $25 \mu \mathrm{g} / \mathrm{mL}$, it had a significant killing effect on most cells. As shown 471 in Fig. 3e, the CCK-8 results more directly showed the gap between PTT and 472 combination therapy, which indicated that combination therapy is a promising 473 treatment strategy. 

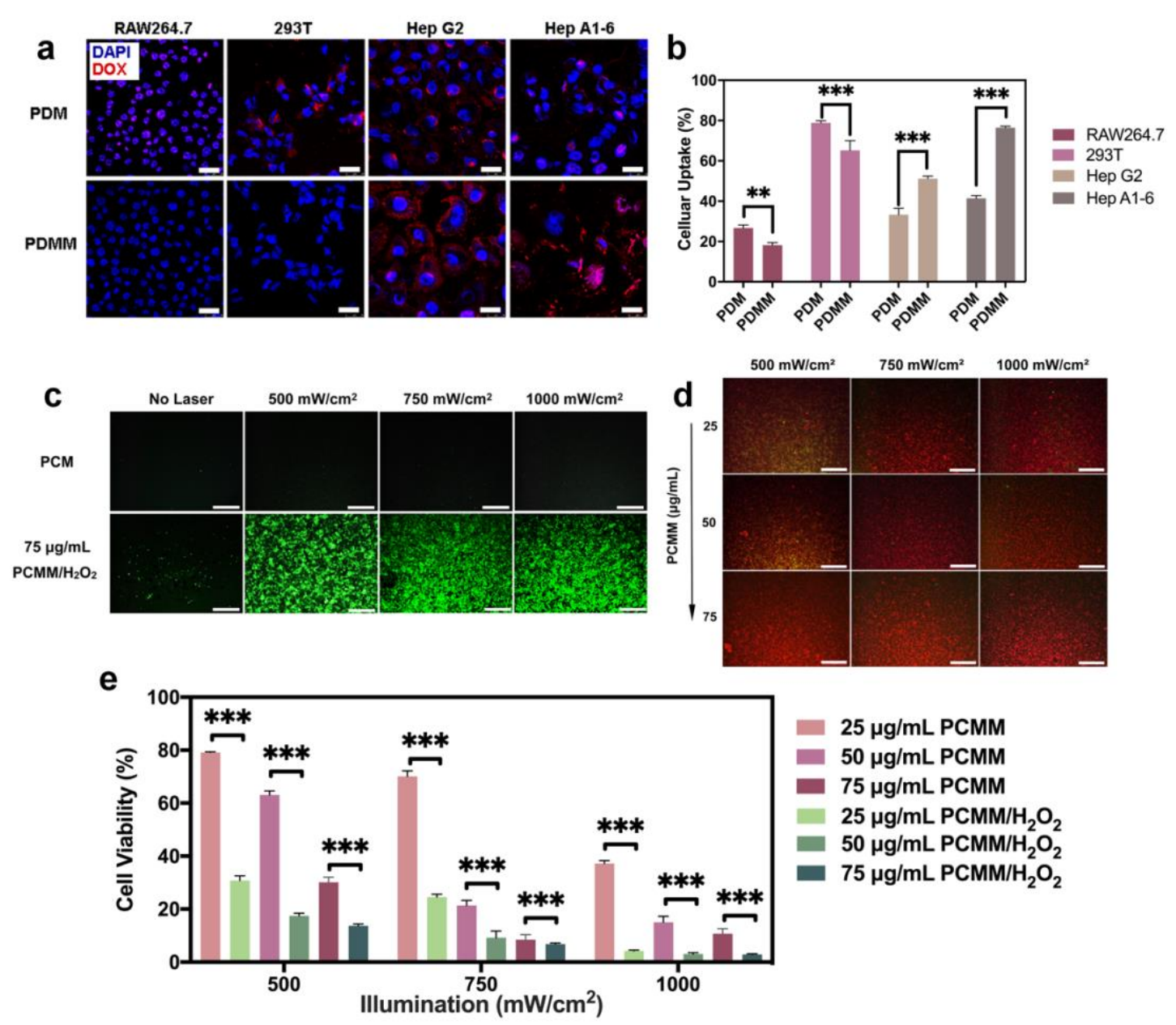

475 Fig. 3. a) Confocal laser images of RAW264.7, 293T, HepG2 and HepA1-6 treated 476 with PDM or PDMM. Scale bar: $25 \mu \mathrm{m}$. b) Quantitative graphs of PDM and PDMM 477 uptake by four types of cells. c) The ability to generate ROS in cells recorded by CLSM.

478 Scale bar: $200 \mu \mathrm{m}$. d) Fluorescence images of HepG2 cells treated with different $479 \mathrm{PCMM} / \mathrm{H}_{2} \mathrm{O}_{2}$ concentrations upon different light intensities for $10 \mathrm{~min}$. Live cells 480 (green); dead cells (red). Scale bar: $500 \mu \mathrm{m}$. e) CCK-8 was used to detect the viability 481 of PTT and combination therapy (*, P<0.05; **, P<0.01; ***, P <0.001).

\section{$482 \quad 3.8$ Exploration of the inhibitory effect of PCMM on HSR}

483 In this context, we are very interested in the inhibitory effect of PCMM on HSR. In this 484 article, we only discuss trigger conditions from PTT. We evaluated the conditions of 
the HSR by monitoring the performance of several important HSPs that are involved. HSP70 and BAG3 are two important HSPs produced by cells during HSR. MCL-1

487 belongs to Bcl-2. The family of antiapoptotic proteins prevents cells from entering the apoptotic state by blocking the release of cytochrome $\mathrm{C}$ from mitochondria(34). As shown in Fig. 4a,b and c, the $0 \mu \mathrm{g} / \mathrm{mL}$ group represented the HSR of $\mathrm{H} 22$ tumour cells when PTT was applied. It could be seen that the greater the light intensity, the more 491 severe the HSR was(18). After HepG2 cells were irradiated with $25 \mu \mathrm{g} / \mathrm{mL}$ of PCMM 492 upon 750 and $1000 \mathrm{~mW} / \mathrm{cm}^{2}$, the expression of HSP70, BAG3 and MCL-1 were down493 regulated with the increase of light intensity. After 50 and $75 \mu \mathrm{g} / \mathrm{mL}$ PCMM treatments, 494 HSP70, BAG3 and MCL-1 all decreased sharply after 750 and $1000 \mathrm{~mW} / \mathrm{cm}^{2}$ 495 irradiation. Combined with the heating curve in Fig. 2c and S2ab, we found that groups 496 with similar expression levels of HSP70, BAG3 and MCL-1 had similar treatment 497 temperature, such as $25 \mu \mathrm{g} / \mathrm{mL}+1000 \mathrm{~mW} / \mathrm{cm}^{2}$ and $50 \mu \mathrm{g} / \mathrm{mL}+500 \mathrm{~mW} / \mathrm{cm}^{2}$. We 498 speculate that this result may be because the MPCM ruptures due to the increase in 499 temperature, and the CTD loaded in the PCMM is released, which has an inhibitory 500 effect on the expression of HSPs. Combined with the drug loading rate, it was 501 calculated that at $14.5 \mu \mathrm{g} / \mathrm{mL}$ of CTD, HSR could be largely suppressed. HSR was 502 absolutely suppressed at $21.75 \mu \mathrm{g} / \mathrm{mL}$ of CTD. Overall, the idea of using PCMM to 503 improve the therapeutic effect of PTT by inhibiting HSR is very promising. 


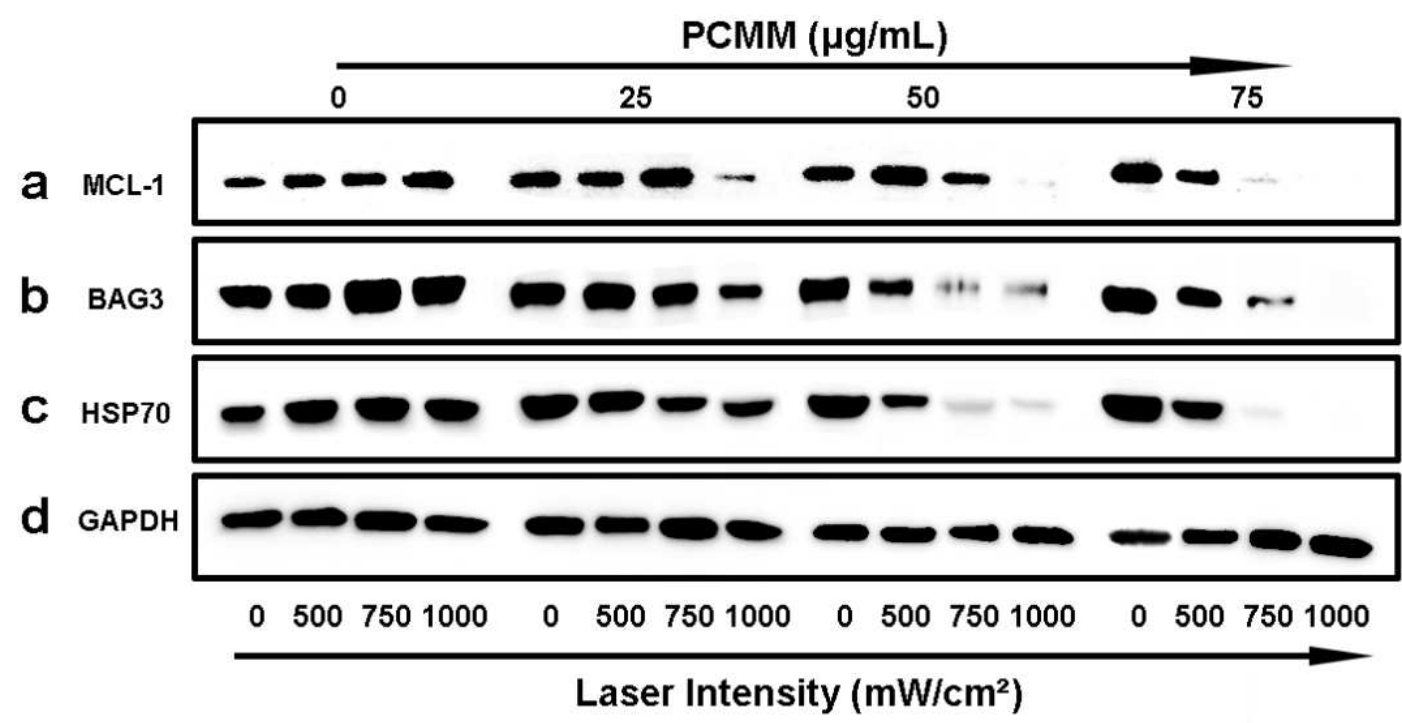

504

505 Fig. 4. a), b), c) and d) are the protein expression of MCL-1, BAG3, HSP70 and

506 GAPDH after treating HepG2 cells with different concentrations of PCMM and

507 different light intensities for $10 \mathrm{~min}$.

\section{3.9 Distribution of PCMM in vivo}

509 To observe the targeting ability of PCMM more intuitively, we monitored the

510 distribution of PCMM in vivo at different times using a live imaging instrument. As

511 shown in Fig. 5a, compared with PCM, PCMM concentrates in the tumour more rapidly.

512 After three days of testing, accumulation of PCMM in the tumour site can still be

513 observed, which shows the long cycle capacity conferred by the MPCM coating. As

514 shown in Fig. 5b, ex vivo images of tumours and organs show that mice in the PCMM

515 group had significantly higher drug residues in tumour and lower hepatorenal

516 accumulation compared to the PCM group. This may be because the membrane coating

517 of macrophages reduces the absorptive capacity of the reticuloendothelial system (RES)

518 of the liver and kidney $(24,35)$. Fig. $5 c$ shows the average fluorescence intensity of the 
519 tumour tissue during the entire process. $12 \mathrm{~h}$ after injection of PCMM, the average 520 fluorescence intensity of the tumour tissue was the highest, and a strong fluorescence 521 signal persisted within three days.

a Time (h)

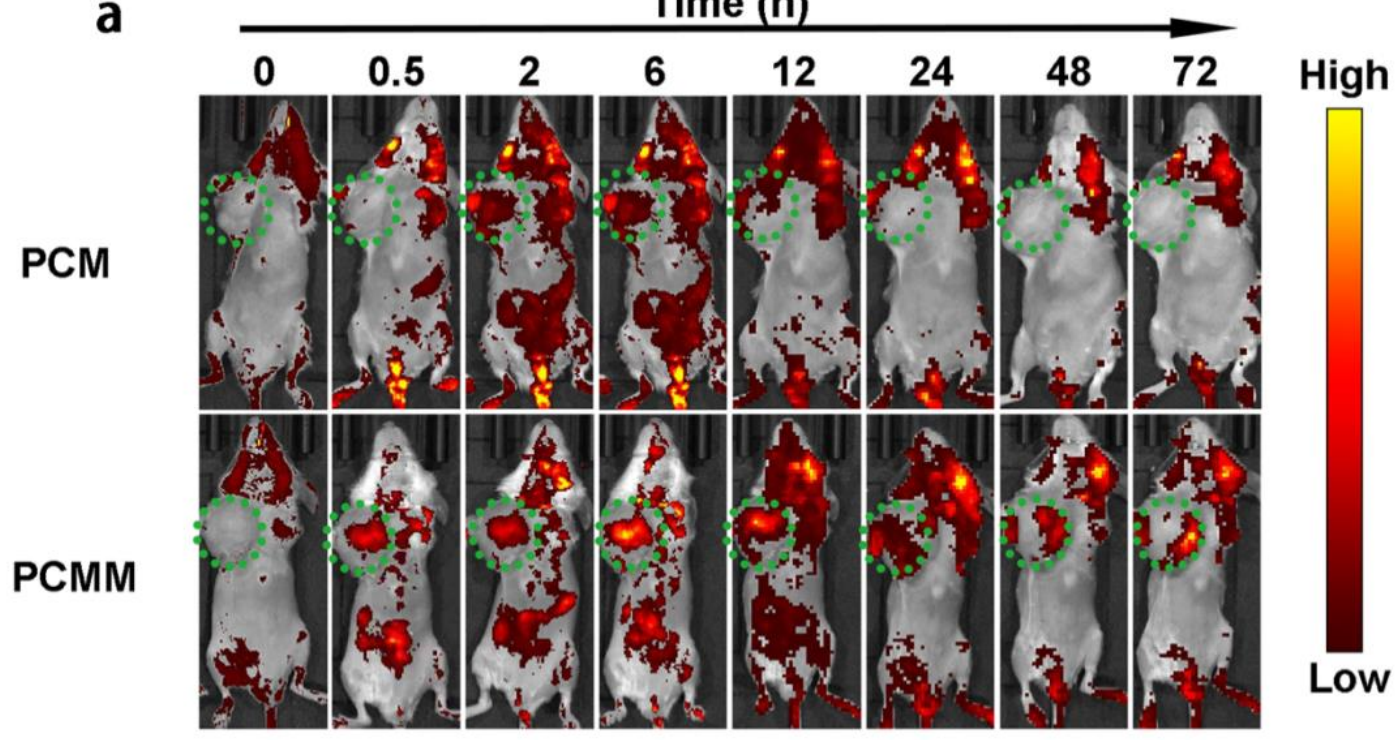

522

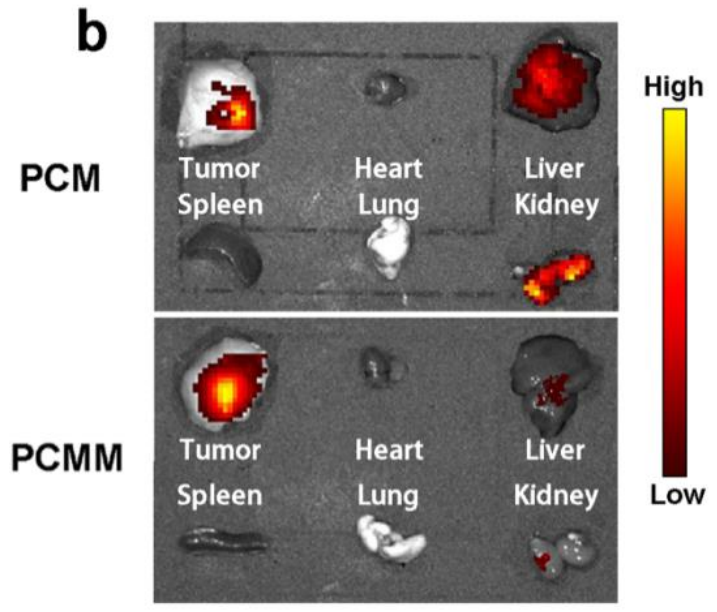

C

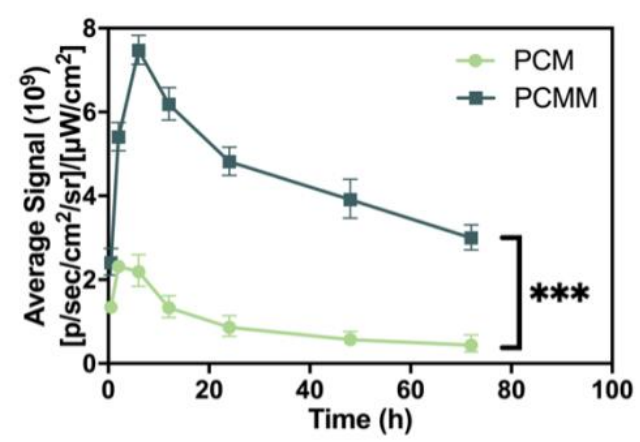

523 Fig. 5. a) Distribution of PCM and PCMM in vivo within 72 h; b) Ex vivo imaging of

524 tumour and organs at $72 \mathrm{~h}$; c) Average signal intensity of the tumour site within $72 \mathrm{~h}$

$525 \quad(*, \mathrm{P}<0.05 ; * *, \mathrm{P}<0.01 ; * * *, \mathrm{P}<0.001)$. 
After investigating the conditions for inhibiting the HSR, we selected the most representative treatment conditions for in vivo study. The in vivo experiment was

529 conducted according to the schedule shown in Fig. 6a. H22 cells were used to establish

530 a tumour model in the right armpit of BALB/c mice at one week in advance. On the

531 first day of treatment, PBS, PMM and PCMM (5 mg/kg, $0.1 \mathrm{mg} / \mathrm{kg}$ CTD, $100 \mu \mathrm{L})$ were

532 intravenously injected into the mice. Within $12 \mathrm{~h}$ after administration, the tumours of

533 the mice were irradiated with an NIR laser $(808 \mathrm{~nm})$ for $10 \mathrm{~min}$.

534 The tumour size was measured every 2 days throughout the experiment, and the tumour

535 volume was plotted over time. Fig. $6 \mathrm{~b}$ shows the changes in tumour volume during the

536 entire experiment. Due to the absence of near-infrared radiation, tumours in the PBS,

537 PMM and PCMM groups showed a natural growth trend. After NIR irradiation, mice

538 treated with PBS showed the same growth trend as PBS alone, which means that light

539 irradiation is harmless. The mice treated with $\mathrm{PMM}+1000 \mathrm{~mW} / \mathrm{cm}^{2}$ showed a strong

540 inhibition of tumour growth in the first ten days, benefitting from the combination

541 therapy of PTT and the Fenton reaction delivered by PMM. Unfortunately, after 12

542 days of treatment, the tumours recurred and grew rapidly. During the entire treatment

543 cycle, the tumours in the PCMM+1000 $\mathrm{mW} / \mathrm{cm}^{2}$ group were effectively suppressed,

544 and no recurrence was observed during the entire experiment. Compared with mice

545 treated with $\mathrm{PMM}+1000 \mathrm{~mW} / \mathrm{cm}^{2}$, this satisfactory result may be due to laser

546 irradiation triggering the release of CTD, thereby inhibiting the HSR of the tumour and

547 enhancing the PTT effect of PCMM combined with chemotherapy and Fenton reaction.

548 Thus, the tumour is completely suppressed. Fig. $6 \mathrm{c}$ shows the body weight of the mice 
during the entire treatment period, which was maintained at a stable level, indicating

550 the safety of the drug. Fig. 6 d shows tumour quality after treatment. Concordant with

551 the above results, the mass of tumour was significantly reduced in PCMM plus three-

552 light intensity laser irradiation group, and the effect was similar in $750 \mathrm{~mW} / \mathrm{cm}^{2}$ and

$5531000 \mathrm{~mW} / \mathrm{cm}^{2}$. Fig. 6e shows representative pictures of the mice and tumours after

554 different treatments. It can be observed that the tumour volume in the group without

555 laser irradiation was significantly larger than that in the group with laser irradiation.

$556 \mathrm{PCMM}+750 \mathrm{~mW} / \mathrm{cm}^{2}$ and $\mathrm{PCMM}+1000 \mathrm{~mW} / \mathrm{cm}^{2}$ have similar therapeutic effects. To

557 achieve favorable PTT antitumour efficacy, the dosage of NIR light usually needed to

558 reach $1.5-4.8 \mathrm{~W} / \mathrm{cm}^{2}$, and the therapeutic platform we developed can achieve effective

559 treatment within the bio-tissue tolerance threshold values $\left(0.33-1.0 \mathrm{~W} / \mathrm{cm}^{2}\right.$ at 808 and

$560980 \mathrm{~nm}$ wavelengths)(36). Fig. 6 f shows H\&E staining of tumour tissue after treatment.

561 It can be seen that results similar to the above results, indicating that PCMM-mediated

562 tumour-targeted combination therapy provides a promising method for cancer 563 treatment.

\section{$564 \quad 3.11$ Immunofluorescence}

565 The tumour tissue of the treated mice was paraffin sectioned for immunofluorescence

566 experiments. As shown in Fig. 6g, the expression level of HIF-1 $\alpha$ in the PBS group was

567 significantly higher than that in the PCMM group treated with laser, indicating that 568 PCMM effectively improved the hypoxic internal environment. The expression of 569 GPX4 (Fig. 6h) also showed a similar trend, which suggests that iron-mediated iron 570 death also had a therapeutic effect $(37,38)$. 


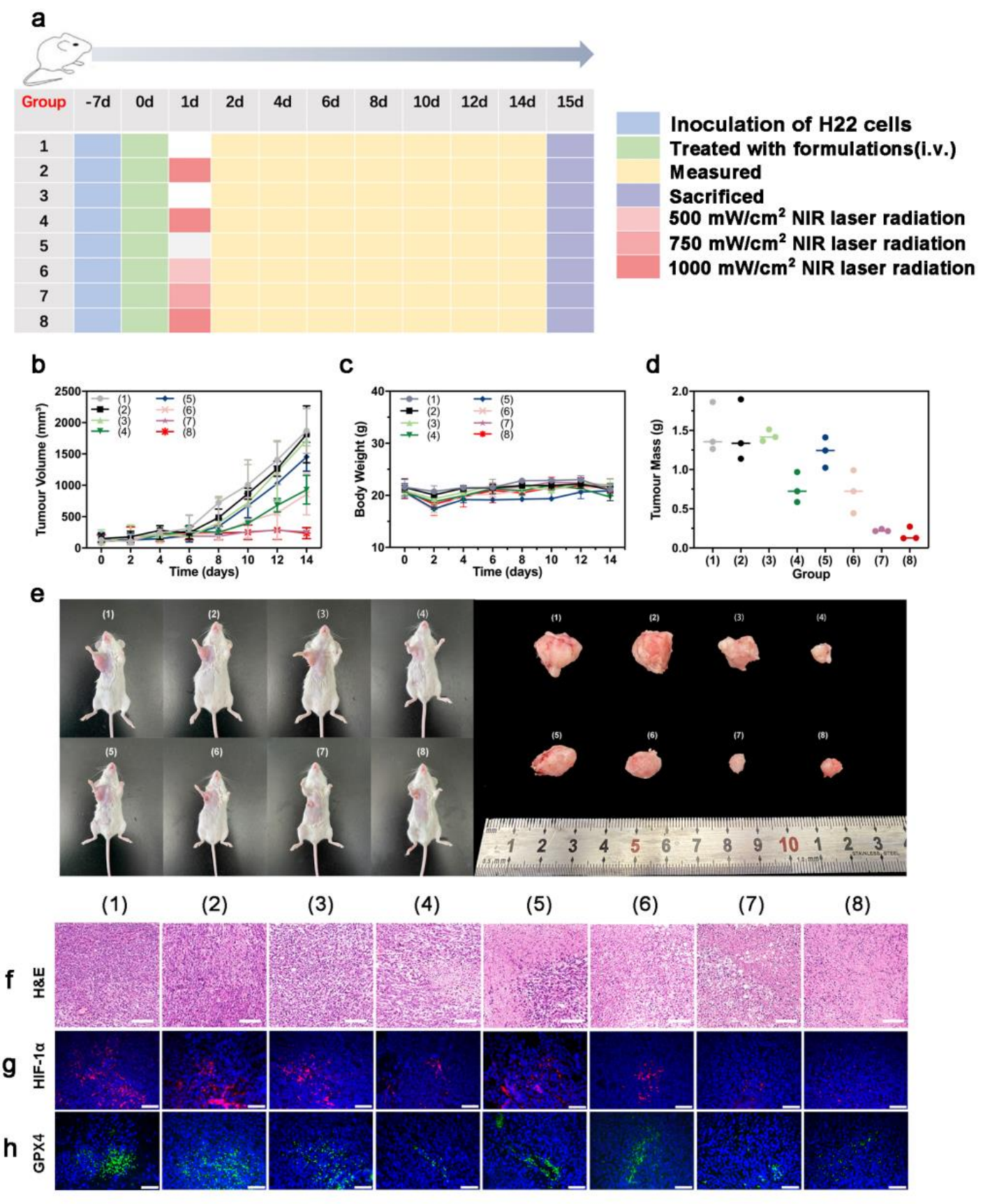

572 Fig. 6. a) Treatment schedule of H22-tumour-bearing mice treated with different

573 formulations. b) Changes in mice tumour volume during the entire treatment period. c)

574 Changes in body weight of the mice during the entire treatment period. d) Tumour

575 quality after treatment e) BALB/c mice treated with different conditions and

576 corresponding tumours. f) H\&E staining of tumour tissue after treatment. Scale bar: 

tumour tissue (green: GPX4, blue: nucleus). Scale bar: $50 \mu$ m.(1) PBS, (2) PBS+1000 mW/cm², (3) PMM, (4) PMM+1000 mW/cm², (5) PCMM, (6) PCMM+500 mW/cm², $\mathrm{P}<0.001)$.

\subsection{In vivo toxicological analysis}

585 The blood was collected from the mice for routine analysis and biochemical 586 examination, and the main organs of the mice (heart, liver, spleen, lung and kidney) 587 were collected and stained with H\&E for histological analysis. As shown in Fig. S8, 588 the main blood parameters (such as RBCs, HGB and PLT) of all groups were not 589 significantly different from those of the PBS group, indicating that mice in each group 590 had no adverse symptoms, such as anaemia. The AST, UREA, and CREA data showed 591 that the liver and kidney function was normal for mice in all groups. In addition, the 592 results of histological analysis (Fig. S9) showed that the main organs of each group of 593 mice maintained normal physiological morphology, and no inflammatory response was 594 observed. In addition, except for the PCMM plus laser irradiation group, tumour 595 metastasis was observed in the liver in all groups. The above results indicated that the 596 toxicity of the nanoparticles in the body is negligible at the tested dose.

\section{Conclusion}


In short, we successfully developed a combined therapy platform (PCMM NPs) based on biomimetic MOF. Under near-infrared laser irradiation, the PCMM heats up rapidly,

600 which is sufficient to trigger the rupture of the coated cell membrane and cause the 601 release of the drug, indicating that the nanoparticles have a successful thermotherapy 602 response release behaviour. The results of the cytotoxicity test showed that the death 603 rate of HepG2 cells after combined treatment was as high as 97\%. The in vivo 604 experimental results showed that PCMM NPs could be delivered after intravenous 605 injection to achieve highly selective tumour targeting, with negligible adverse effects 606 on normal tissues. Both in vitro and in vivo results showed that the therapeutic efficacy 607 of $\mathrm{PCMM}+750 \mathrm{~mW} / \mathrm{cm}^{2}$ and $\mathrm{PCMM}+1000 \mathrm{~mW} / \mathrm{cm}^{2}$ was very similar, indicating that 608 the combination therapy mediated by PCMM was sufficient to effectively inhibit 609 tumour growth under the laser irradiation at the intensity within the bio-tissue tolerance 610 threshold (330-1000 $\left.\mathrm{mW} / \mathrm{cm}^{2}\right)$. We explored the role of PCMM NPs in inhibiting the 611 HSR in photothermal therapy and found that $14.5 \mu \mathrm{g} / \mathrm{mL}$ of CTD could effectively 612 inhibit the HSR of tumour cells. In summary, due to the versatility of its structure and 613 function, PCMM can be used as a promising nanodrug delivery system for future cancer 614 treatments.

615 ASSOCIATED CONTENT

616 Supporting Information.

617 The following files are available free of charge.

618 ABBREVIATIONS

619 
621 response; MPCM macrophage cell membranes; CTD cantharidin; TME tumour

622 microenvironment.

\section{Acknowledgments}

624 Authors are grateful to their respective institutions for support.

\section{Author Contributions}

626 Xiao Cheng, Ye Liu and Zhaoming Guo conceived the project, planned the experiment, 627 and interpreted the data. Jijun $\mathrm{Fu}$, Hao Zhou and Dong Wang provided technical support.

628 Junke Leng and Xiaofeng Dai performed fow cytometry for intercellular uptake 629 quantifcation. Kun Ma and Changhao Cui contributed to the manuscript writing and 630 editing.

\section{Funding}

632 This work is financially supported by the Dalian Science and Technology Innovation 633 Fund (2019J12GX045) and National Natural Science Foundation of China (81603049), 634 the Natural Science Foundation of Liaoning Province (2019-MS-059) and the 635 Fundamental Research Funds for the Central Universities (DUT20JC08).

636 Availability of data and materials

637 Not applicable.

638 Declarations

639 Ethics approval and consent to participate 
640 SPF BALB/c mice were purchased from Liaoning Changsheng Biotechnology Co., Ltd.

641 (Liaoning, China). All animal procedures in this investigation were approved by the

642 Institutional Animal Care and Use Committee of Dalian University of Technology.

\section{Consent for publication}

644 No individual person's data were included in this research.

\section{Competing interests}

646 Authors declare there are no competing interests, fnancial and non-fnancial, in relation

647 to the work described.

\section{REFERENCES}

1. Dai $Y, X u C$, Sun $X$, Chen X. Nanoparticle design strategies for enhanced anticancer therapy by exploiting the tumour microenvironment. Chemical Society Reviews. 2017;46(12):3830-52.

653 2. Xiao Y, Yu D. Tumor microenvironment as a therapeutic target in cancer. Pharmacology \& 654 Therapeutics. 2020:107753.

655 3. Lin $\mathrm{H}$, Chen Y, Shi J. Nanoparticle-triggered in situ catalytic chemical reactions for tumour-specific 656 therapy. Chemical Society Reviews. 2018;47(6):1938-58.

657 4. Li W-P, Su C-H, Chang Y-C, Lin Y-J, Yeh C-S. Ultrasound-Induced Reactive Oxygen Species Mediated 658 Therapy and Imaging Using a Fenton Reaction Activable Polymersome. ACS Nano. 2016;10(2):2017-27.

659 5. Chen Q, Feng L, Liu J, Zhu W, Dong Z, Wu Y, et al. Intelligent Albumin-MnO2 Nanoparticles as pH660 /H2O2-Responsive Dissociable Nanocarriers to Modulate Tumor Hypoxia for Effective Combination 661 Therapy. Advanced Materials. 2016;28(33):7129-36.

662 6. Fu J, Shao Y, Wang L, Zhu Y. Lysosome-controlled efficient ROS overproduction against cancer cells 663 with a high pH-responsive catalytic nanosystem. Nanoscale. 2015;7(16):7275-83.

664 7. Kaelin WG, Jr., Ratcliffe PJ, Semenza GL. Pathways for Oxygen Regulation and Homeostasis: The 6652016 Albert Lasker Basic Medical Research Award. JAMA. 2016;316(12):1252-3.

666 8. Chen XY, Zhang HL, Zhang M, Zhao PR, Song RX, Gong T, et al. Amorphous Fe-Based Nanoagents 667 for Self-Enhanced Chemodynamic Therapy by Re-Establishing Tumor Acidosis. Advanced Functional 668 Materials. 2020;30(6):9.

669 9. Tang Z, Zhang H, Liu Y, Ni D, Zhang H, Zhang J, et al. Antiferromagnetic Pyrite as the Tumor 670 Microenvironment-Mediated Nanoplatform for Self-Enhanced Tumor Imaging and Therapy. Adv Mater. $6712017 ; 29(47)$.

672 10. Bokare AD, Choi W. Review of iron-free Fenton-like systems for activating $\mathrm{H} 2 \mathrm{O} 2$ in advanced 
oxidation processes. J Hazard Mater. 2014;275:121-35.

674 11. Chen Q, Luo Y, Du W, Liu Z, Zhang S, Yang J, et al. Clearable Theranostic Platform with a pH675 Independent Chemodynamic Therapy Enhancement Strategy for Synergetic Photothermal Tumor 676 Therapy. ACS Appl Mater Interfaces. 2019;11(20):18133-44.

677 12. Min H, Qi Y, Zhang Y, Han X, Cheng K, Liu Y, et al. A Graphdiyne Oxide-Based Iron Sponge with 678 Photothermally Enhanced Tumor-Specific Fenton Chemistry. Adv Mater. 2020;32(31):e2000038.

679 13. Zha Z, Deng Z, Li Y, Li C, Wang J, Wang S, et al. Biocompatible polypyrrole nanoparticles as a novel 680 organic photoacoustic contrast agent for deep tissue imaging. Nanoscale. 2013;5(10):4462-7.

681 14. Liu T, Liu W, Zhang M, Yu W, Gao F, Li C, et al. Ferrous-Supply-Regeneration Nanoengineering for 682 Cancer-Cell-Specific Ferroptosis in Combination with Imaging-Guided Photodynamic Therapy. ACS Nano. 683 2018;12(12):12181-92.

684 15. Danics L, Schvarcz CA, Viana P, Vancsik T, Krenacs T, Benyo Z, et al. Exhaustion of Protective Heat 685 Shock Response Induces Significant Tumor Damage by Apoptosis after Modulated Electro-Hyperthermia 686 Treatment of Triple Negative Breast Cancer Isografts in Mice. Cancers. 2020;12(9).

687 16. Ernst A, Hennel R, Krombach J, Kapfhammer H, Brix N, Zuchtriegel G, et al. Priming of Anti-tumor 688 Immune Mechanisms by Radiotherapy Is Augmented by Inhibition of Heat Shock Protein 90. Frontiers 689 in Oncology. 2020;10.

690 17. Guo ZM, Liu Y, Cheng X, Wang D, Guo SB, Jia ML, et al. Versatile biomimetic cantharidin-tellurium 691 nanoparticles enhance photothermal therapy by inhibiting the heat shock response for combined 692 tumor therapy. Acta Biomater. 2020;110:208-20.

693 18. Kim JA, Kim Y, Kwon BM, Han DC. The natural compound cantharidin induces cancer cell death 694 through inhibition of heat shock protein 70 (HSP70) and Bcl-2-associated athanogene domain 3 (BAG3) 695 expression by blocking heat shock factor 1 (HSF1) binding to promoters. J Biol Chem. 696 2013;288(40):28713-26.

697 19. Hu C, Lei T, Wang Y, Cao J, Yang X, Qin L, et al. Phagocyte-membrane-coated and laser-responsive 698 nanoparticles control primary and metastatic cancer by inducing anti-tumor immunity. Biomaterials. 699 2020;255:120159.

700 20. Li SY, Cheng H, Xie BR, Qiu WX, Zeng JY, Li CX, et al. Cancer Cell Membrane Camouflaged Cascade 701 Bioreactor for Cancer Targeted Starvation and Photodynamic Therapy. ACS Nano. 2017;11(7):7006-18.

702 21. Cao H, Dan Z, He X, Zhang Z, Yu H, Yin Q, et al. Liposomes Coated with Isolated Macrophage 703 Membrane Can Target Lung Metastasis of Breast Cancer. ACS Nano. 2016;10(8):7738-48.

704 22. Jin K, Luo Z, Zhang B, Pang Z. Biomimetic nanoparticles for inflammation targeting. Acta Pharm Sin 705 B. 2018;8(1):23-33.

706 23. Jin K, Luo Z, Zhang B, Pang Z. Biomimetic nanoparticles for inflammation targeting. Acta 707 Pharmaceutica Sinica B. 2018;8(1):23-33.

708 24. Xuan M, Shao J, Dai L, Li J, He Q. Macrophage Cell Membrane Camouflaged Au Nanoshells for in 709 Vivo Prolonged Circulation Life and Enhanced Cancer Photothermal Therapy. ACS Appl Mater Interfaces. $710 \quad$ 2016;8(15):9610-8.

711 25. Lee $M H$, Yang Z, Lim CW, Lee YH, Dongbang S, Kang C, et al. Disulfide-Cleavage-Triggered 712 Chemosensors and Their Biological Applications. Chemical Reviews. 2013;113(7):5071-109.

713 26. Kim J, Cho HR, Jeon H, Kim D, Song C, Lee N, et al. Continuous O(2)-Evolving MnFe(2)O(4) 714 Nanoparticle-Anchored Mesoporous Silica Nanoparticles for Efficient Photodynamic Therapy in Hypoxic 715 Cancer. J Am Chem Soc. 2017;139(32):10992-5.

716 27. Prasad P, Gordijo CR, Abbasi AZ, Maeda A, Ip A, Rauth AM, et al. Multifunctional Albumin-MnO2 
717 Nanoparticles Modulate Solid Tumor Microenvironment by Attenuating Hypoxia, Acidosis, Vascular

718 Endothelial Growth Factor and Enhance Radiation Response. Acs Nano. 2014;8(4):3202-12.

719 28. Chen X, Zhang M, Li S, Li L, Zhang L, Wang T, et al. Facile synthesis of polypyrrole@metal-organic

720 framework core-shell nanocomposites for dual-mode imaging and synergistic chemo-photothermal

721 therapy of cancer cells. J Mater Chem B. 2017;5(9):1772-8.

722 29. Hong JY, Yoon H, Jang J. Kinetic study of the formation of polypyrrole nanoparticles in water-soluble

723 polymer/metal cation systems: a light-scattering analysis. Small. 2010;6(5):679-86.

724 30. Lin L-S, Song J, Song L, Ke K, Liu Y, Zhou Z, et al. Simultaneous Fenton-like Ion Delivery and 725 Glutathione Depletion by MnO2-Based Nanoagent to Enhance Chemodynamic Therapy. Angewandte 726 Chemie-International Edition. 2018;57(18):4902-6.

727 31. Roper DK, Ahn W, Hoepfner M. Microscale Heat Transfer Transduced by Surface Plasmon Resonant 728 Gold Nanoparticles. The Journal of Physical Chemistry C. 2007;111(9):3636-41.

729 32. Dong X, Yin W, Yu J, Dou R, Bao T, Zhang X, et al. Mesoporous Bamboo Charcoal Nanoparticles as a

730 New Near-Infrared Responsive Drug Carrier for Imaging-Guided Chemotherapy/Photothermal

731 Synergistic Therapy of Tumor. Advanced Healthcare Materials. 2016;5(13):1627-37.

732 33. Chen D, Wang C, Nie X, Li S, Li R, Guan M, et al. Photoacoustic Imaging Guided Near-Infrared

733 Photothermal Therapy Using Highly Water-Dispersible Single-Walled Carbon Nanohorns as Theranostic

734 Agents. Advanced Functional Materials. 2014;24(42):6621-8.

735 34. Yang J, Liu XS, Bhalla K, Kim CN, Ibrado AM, Cai JY, et al. Prevention of apoptosis by BCl-2: Release 736 of cytochrome $\mathrm{c}$ from mitochondria blocked. Science. 1997;275(5303):1129-32.

737 35. Xuan M, Shao J, Dai L, He Q, Li J. Macrophage Cell Membrane Camouflaged Mesoporous Silica 738 Nanocapsules for In Vivo Cancer Therapy. Adv Healthc Mater. 2015;4(11):1645-52.

739 36. Lin H, Gao S, Dai C, Chen Y, Shi J. A Two-Dimensional Biodegradable Niobium Carbide (MXene) for 740 Photothermal Tumor Eradication in NIR-I and NIR-II Biowindows. Journal of the American Chemical 741 Society. 2017;139(45):16235-47.

742 37. Xu B, Cui Y, Wang W, Li S, Lyu C, Wang S, et al. Immunomodulation-Enhanced Nanozyme-Based 743 Tumor Catalytic Therapy. Adv Mater. 2020;32(33):e2003563.

744 38. Liu T, Liu W, Zhang M, Yu W, Gao F, Li C, et al. Ferrous-Supply-Regeneration Nanoengineering for 745 Cancer-Cell-Specific Ferroptosis in Combination with Imaging-Guided Photodynamic Therapy. Acs Nano. 746 2018;12(12):12181-92. 

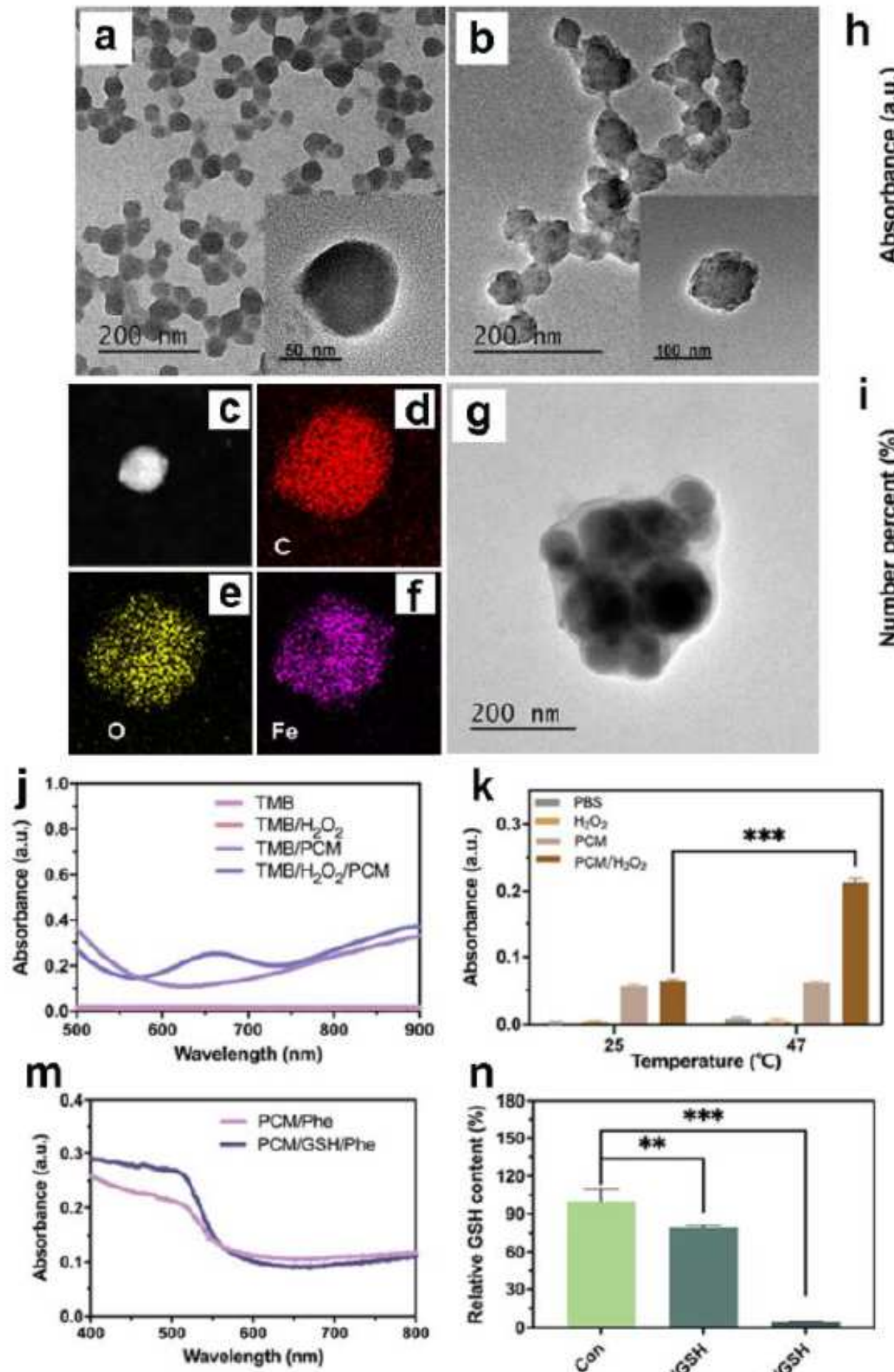
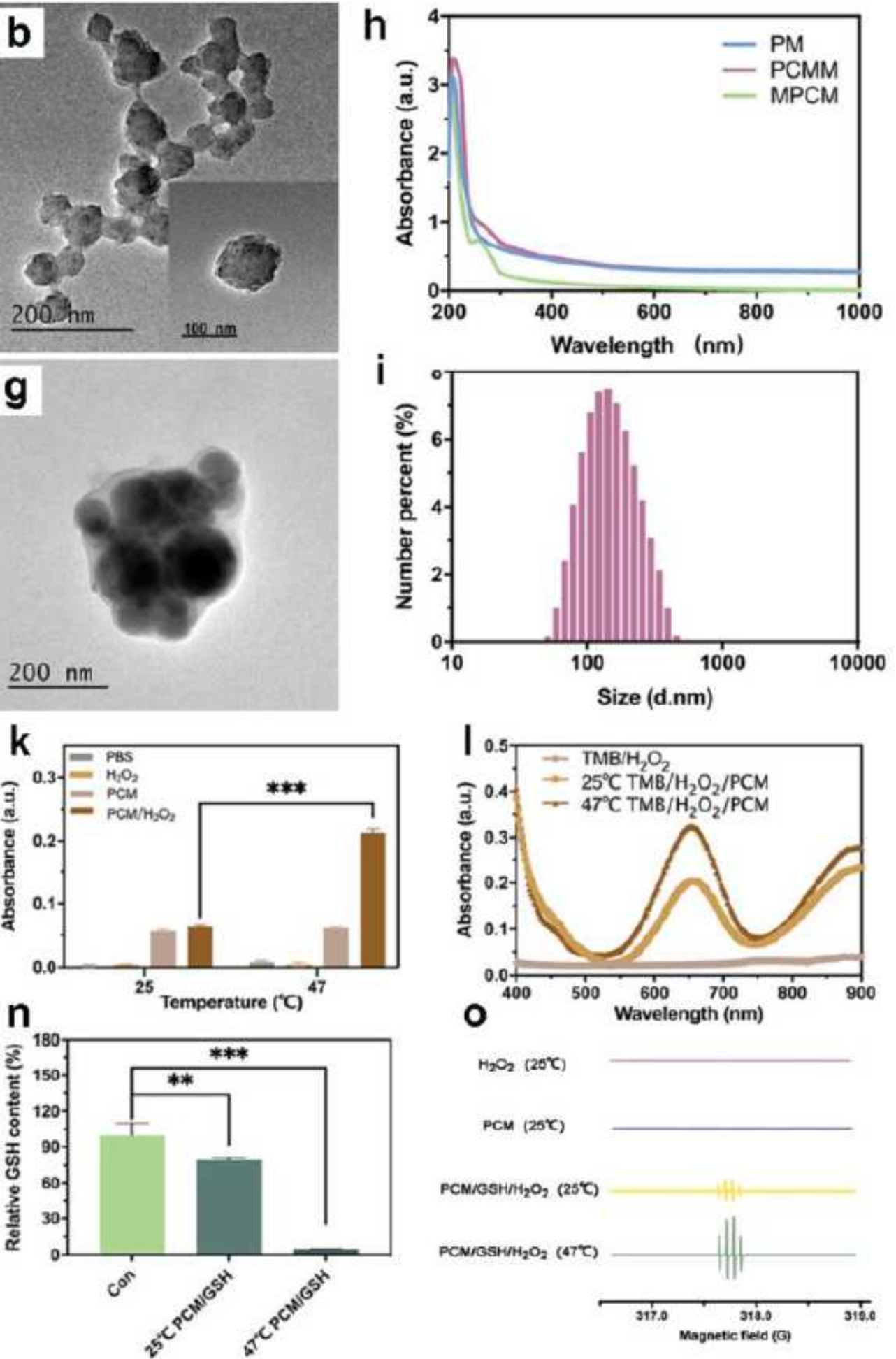

$\mathrm{H}_{2} \mathrm{O}_{2}\left(26^{\circ} \mathrm{C}\right)$

PCM (25r)

$\mathrm{PCM} / \mathrm{GSH} / \mathrm{H}_{2} \mathrm{O}_{2}\left(2^{\circ} \mathrm{C}\right)$

PCN/OSH $/ \mathrm{H}_{2} \mathrm{O}_{2}$ (47\%)

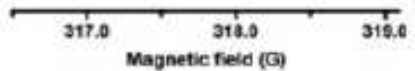

\section{Figure 1}

a) TEM image of PPy NPs. b) TEM image of PM and c) corresponding dark field TEM image and element mapping of $d$ ) carbon ( $\mathrm{C}$, red), e) oxygen ( $\mathrm{O}$, yellow) and f) iron (Fe, purple) in the selected area. g) TEM image of PCMM. h) UV-Vis absorption spectra of PM, MPCM and PCMM. i) Average hydrodynamic size 
of PCMM. j) UV-Vis absorption spectra of TMB solutions treated with different groups. k) Absorbance of TMB at $650 \mathrm{~nm}$ after incubation for 5 min under the specified conditions. I) UV-Vis absorption spectra of TMB and $\mathrm{H} 2 \mathrm{O} 2$ incubated with PCM at different temperatures. $\mathrm{m}$ ) UV-Vis absorption spectra of the $\mathrm{PCM} / \mathrm{Phe}$ and PCM/GSH/Phe groups. $n$ ) Evaluation of the GSH consumption capacity of PCM NPs at different temperatures with the GSH Kit. o) EPR spectrum of PCM with DMPO as the capture agent under specified conditions. *, $\mathrm{P}<0.05 ; * \star, \mathrm{P}<0.01 ; * \star \star, \mathrm{P}<0.001$.
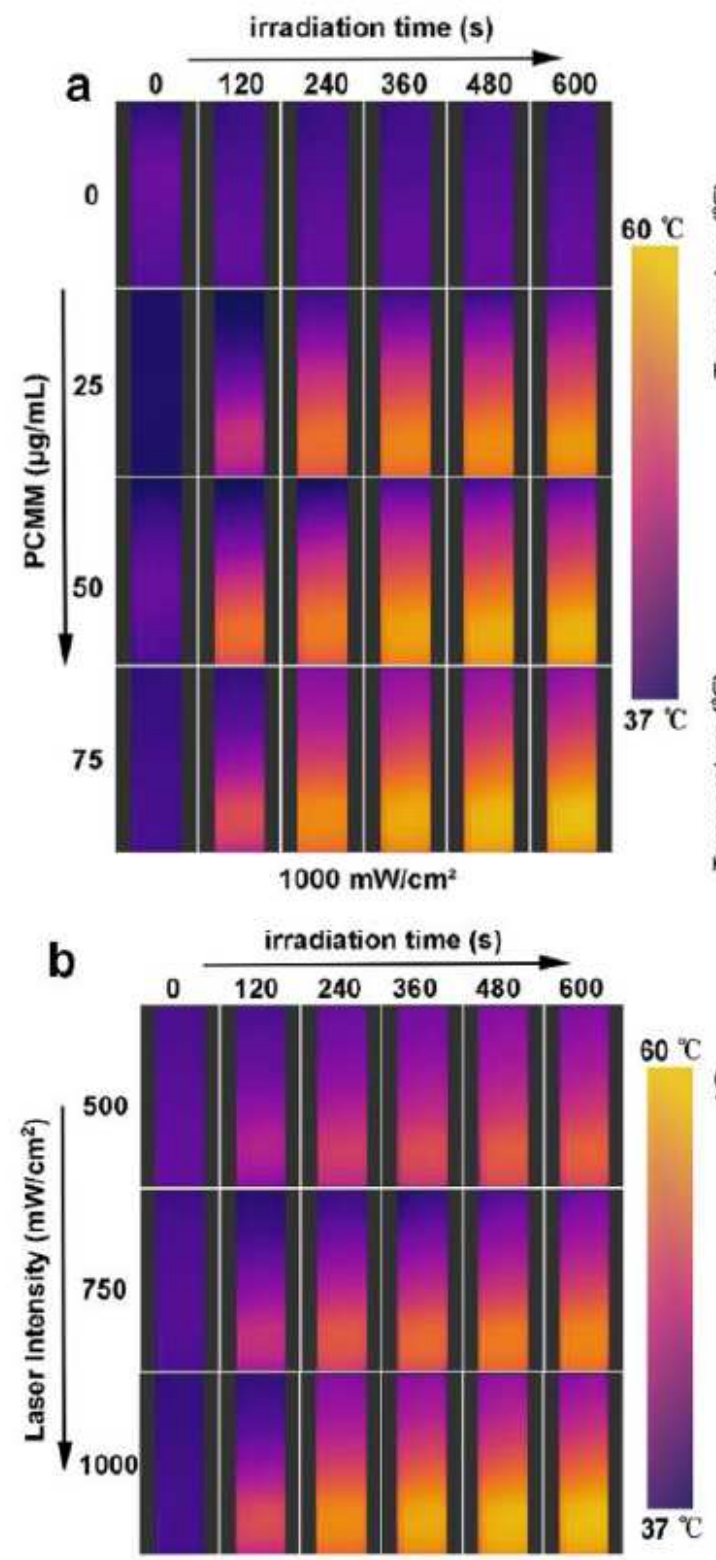

$75 \mu \mathrm{g} / \mathrm{mL}$

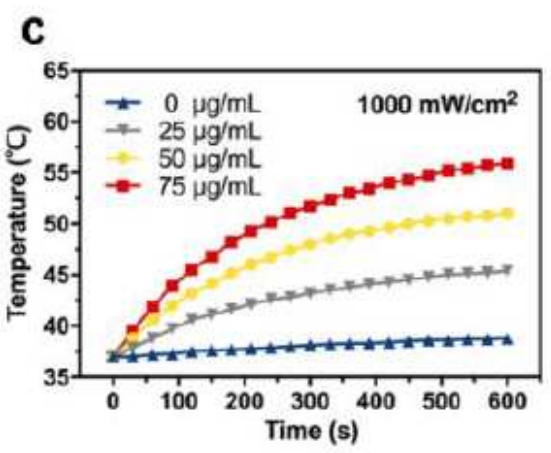

d
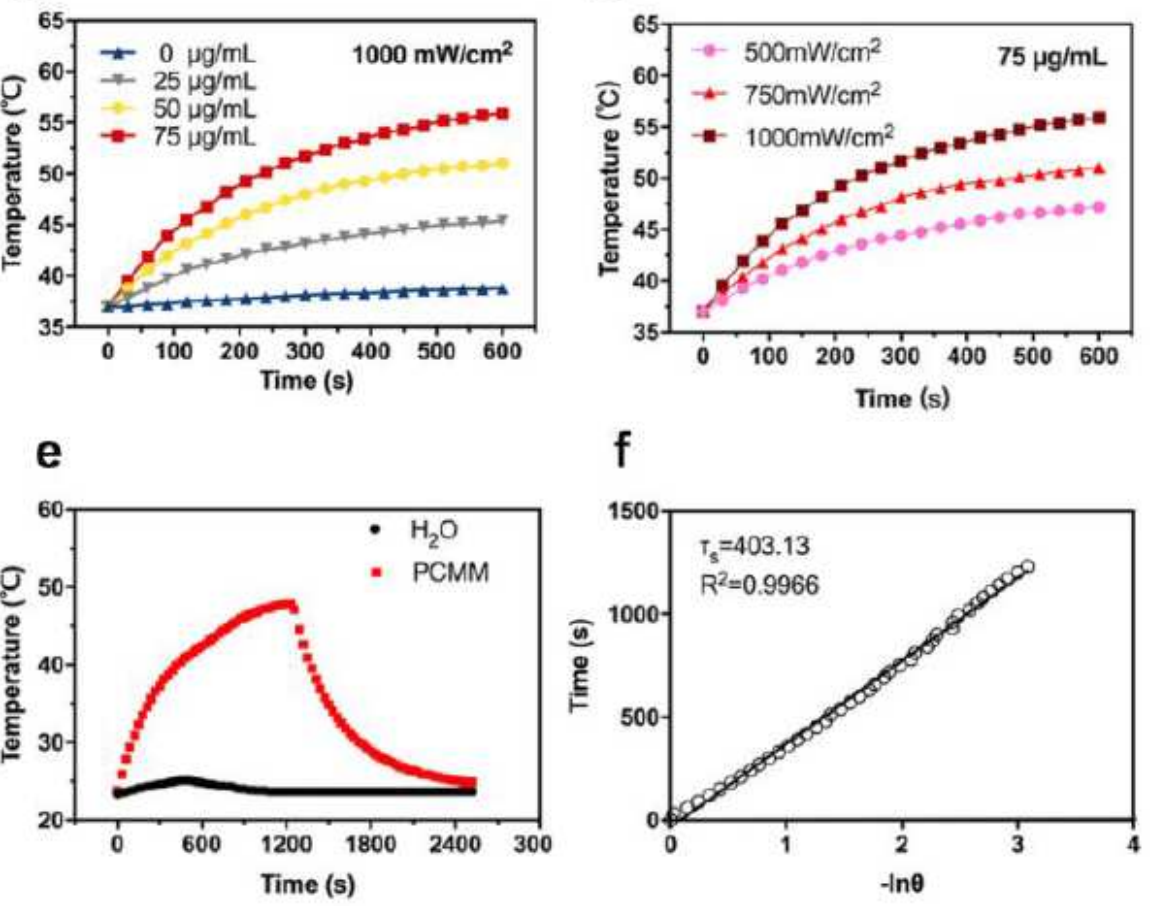

g

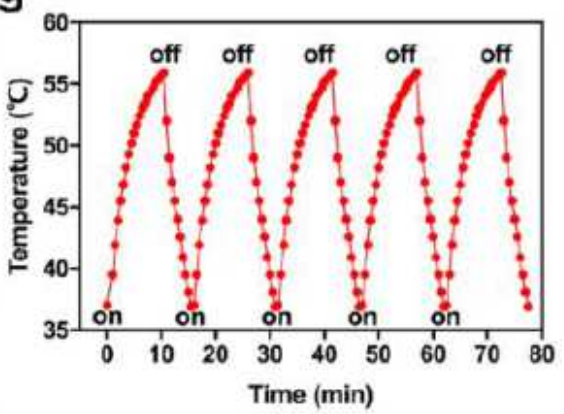

h

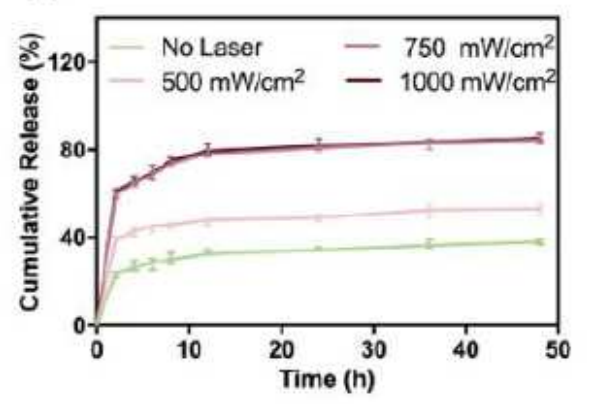

Figure 2

Photothermal performance of PCMM in vitro. a) Near-infrared thermal images of PCMM suspension at three concentrations with $1000 \mathrm{~mW} / \mathrm{cm} 2$ Near-infrared laser irradiation $(808 \mathrm{~nm})$ for $10 \mathrm{~min}$ and b) Nearinfrared thermal images of PCMM suspension $(75 \mu \mathrm{g} / \mathrm{mL})$ with three light intensities of Near-infrared laser irradiation (808 nm) for 10 min. c) The temperature (ه) of PCMM at $1000 \mathrm{~mW} / \mathrm{cm} 2$ Near-infrared 
laser irradiation $(808 \mathrm{~nm})$ for 10 min. d) The temperature (『) of PCMM $(75 \mu \mathrm{g} / \mathrm{mL})$ with three light intensities of Near-infrared laser irradiation ( $808 \mathrm{~nm}$ ) for $10 \mathrm{~min}$. e) Heating and cooling curves of the PCMM suspension $(75 \mu \mathrm{g} / \mathrm{mL})$ and deionized water at room temperature. f) The plot of cooling time versus negative natural logarithm of the temperature driving force. g) Temperature change of the PCMM suspension $(75 \mu \mathrm{g} / \mathrm{mL})$ under laser irradiation for 5 on/off cycles. h) Drug release of PCMM with three light intensities of Near-infrared laser irradiation $(808 \mathrm{~nm})$ for $10 \mathrm{~min}$. Unless otherwise specified, the photothermal experiments were performed at $37^{\circ} \mathrm{C}$.
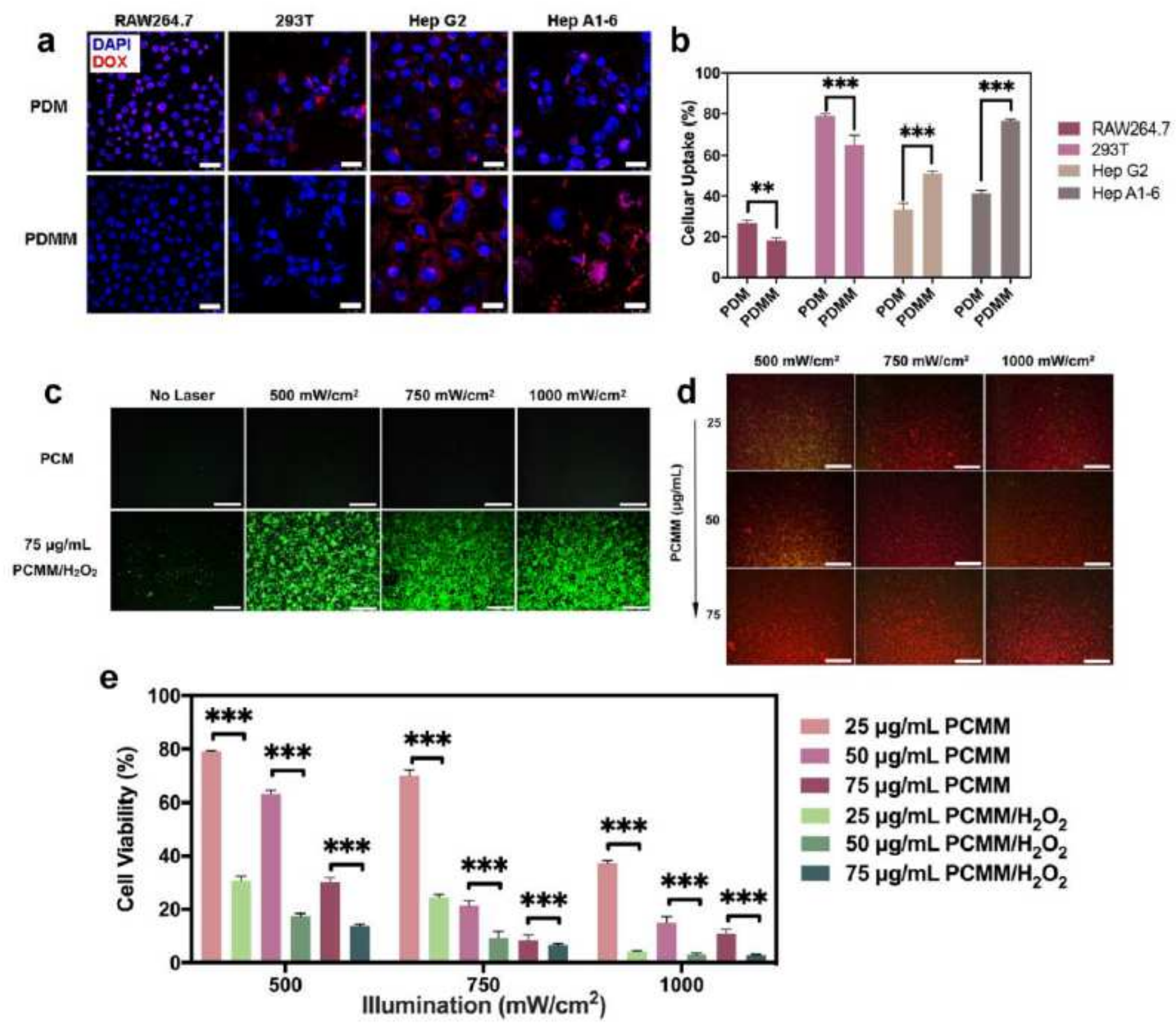

Figure 3

a) Confocal laser images of RAW264.7, 293T, HepG2 and HepA1-6 treated with PDM or PDMM. Scale bar: $25 \mu \mathrm{m}$. b) Quantitative graphs of PDM and PDMM uptake by four types of cells. c) The ability to generate ROS in cells recorded by CLSM. Scale bar: $200 \mu \mathrm{m}$. d) Fluorescence images of HepG2 cells treated with different PCMM/H2O2 concentrations upon different light intensities for 10 min. Live cells (green); dead 
cells (red). Scale bar: $500 \mu \mathrm{m}$. e) CCK-8 was used to detect the viability of PTT and combination therapy $(*, P<0.05 ; * \star, P<0.01 ; * \star *, P<0.001)$.

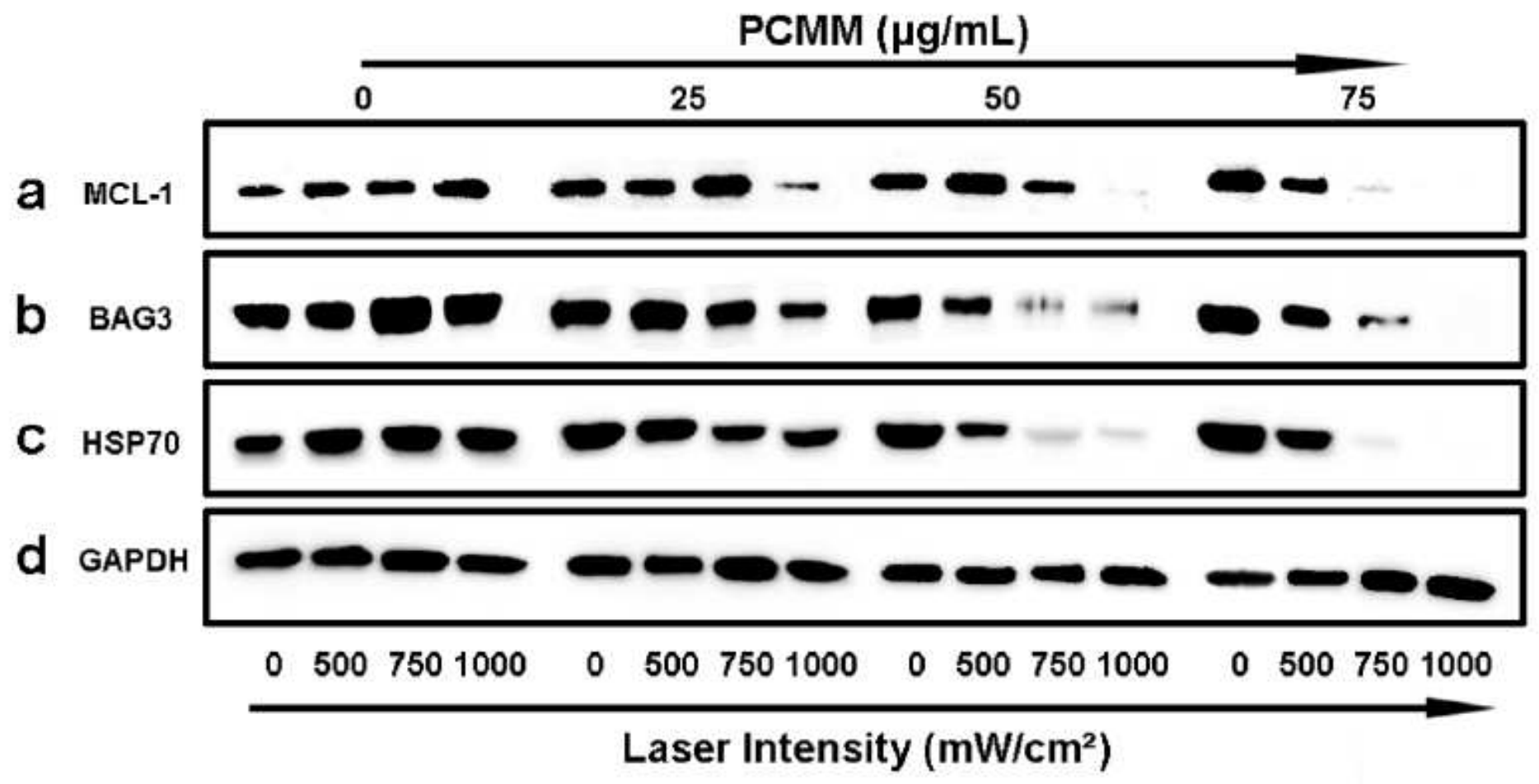

Figure 4

a), b), c) and d) are the protein expression of MCL-1, BAG3, HSP70 and GAPDH after treating HepG2 cells with different concentrations of PCMM and different light intensities for $10 \mathrm{~min}$. 


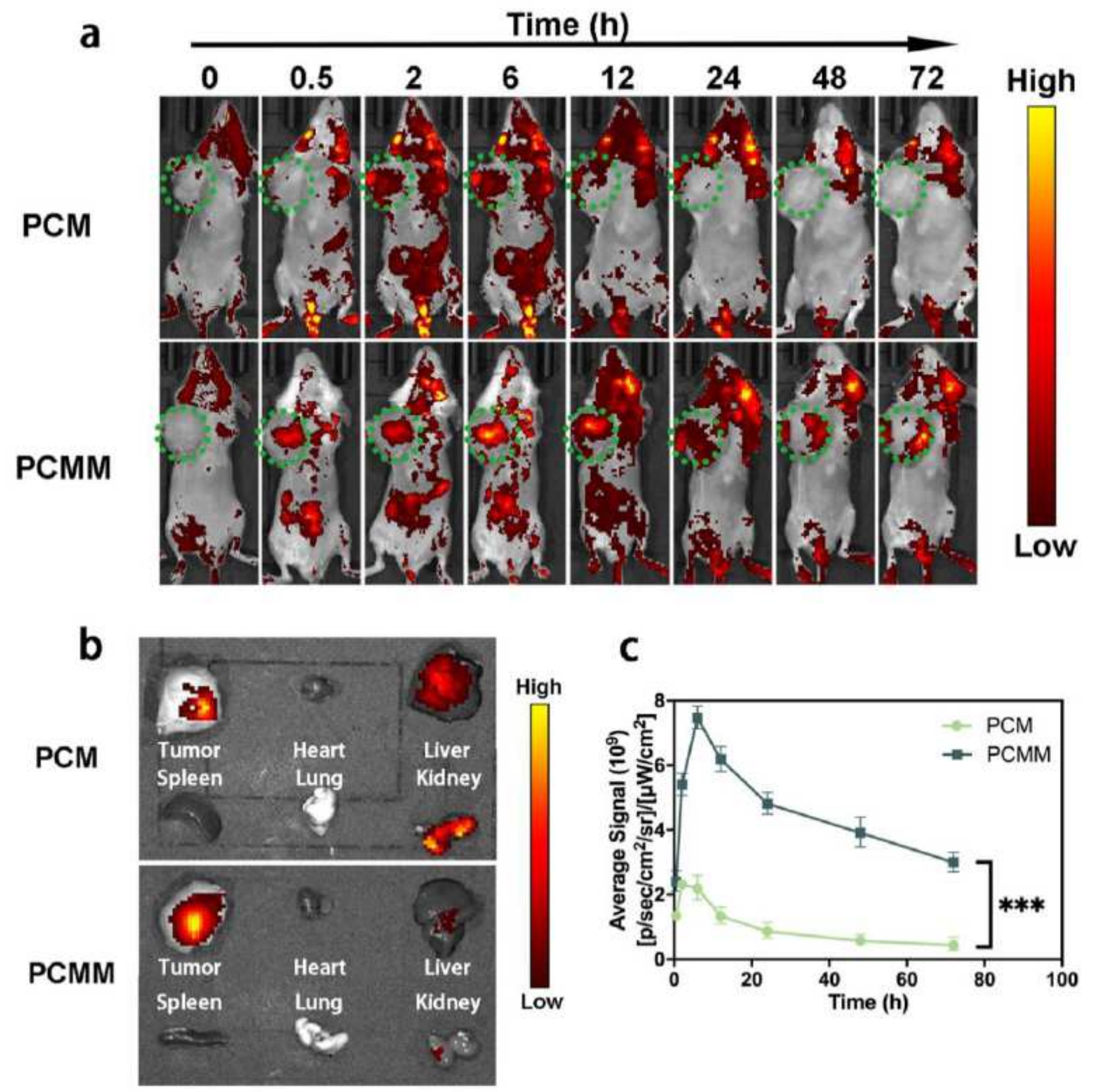

Figure 5

a) Distribution of PCM and PCMM in vivo within $72 \mathrm{~h}$; b) Ex vivo imaging of tumour and organs at $72 \mathrm{~h}$;

c) Average signal intensity of the tumour site within $72 \mathrm{~h}(*, \mathrm{P}<0.05 ; * \star, P<0.01 ; * \star \star, P<0.001)$. 

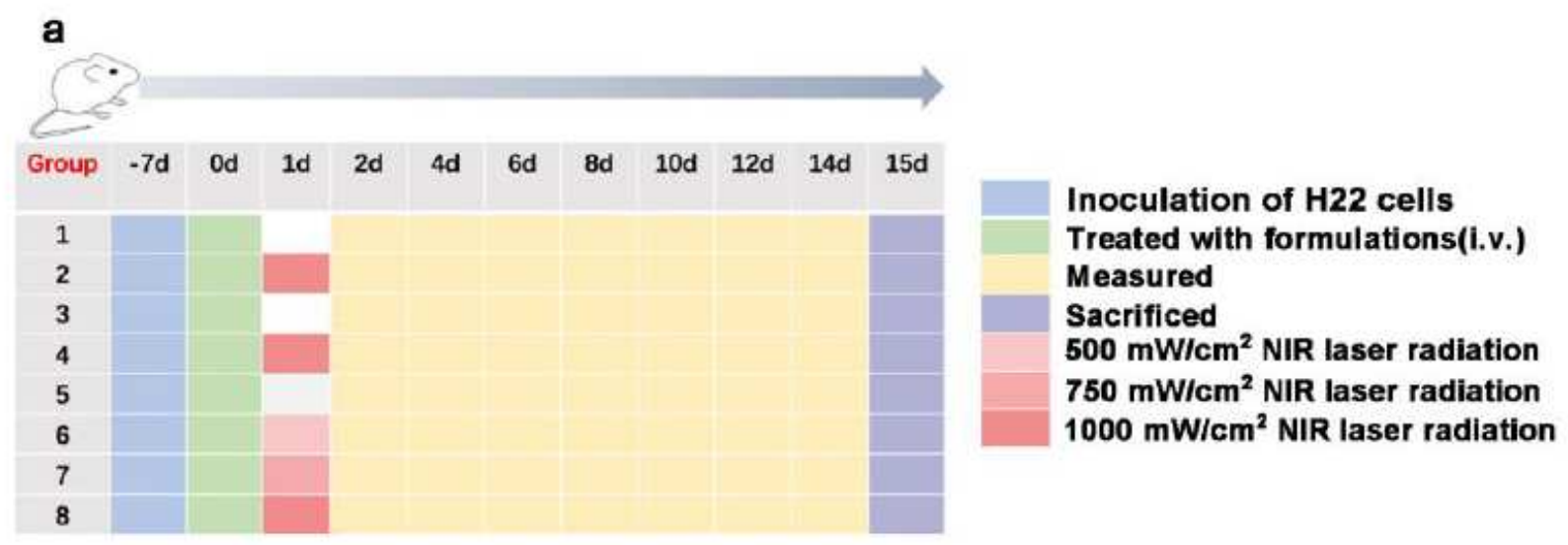

b

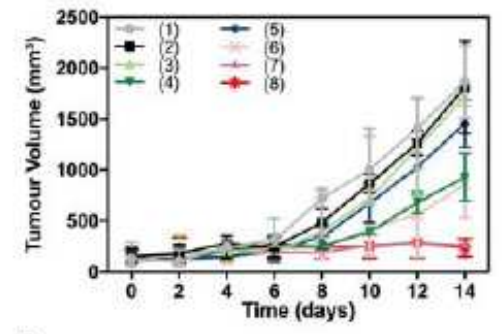

C

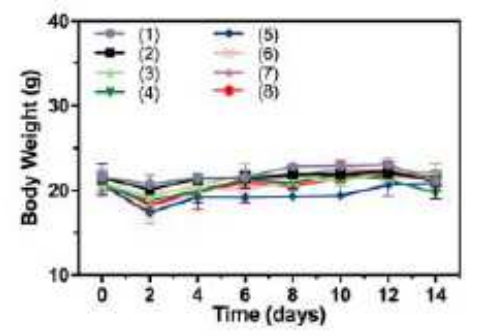

d

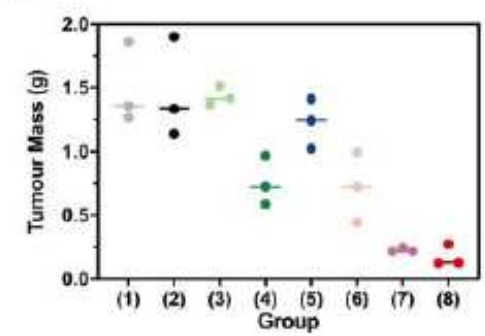

e

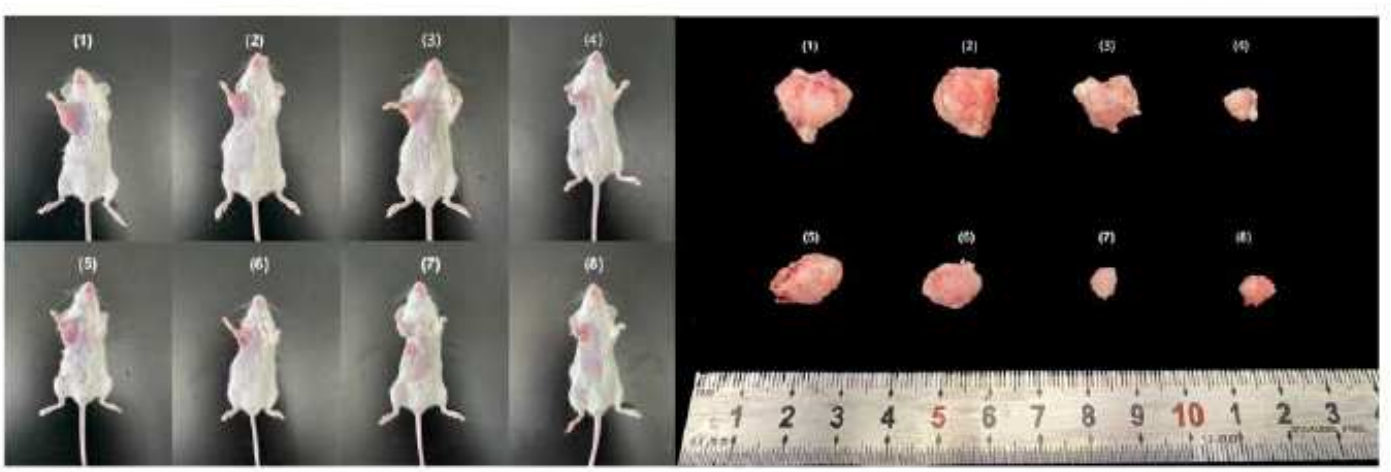

(1)

(2)

(3)

(4)

(5)

(6)

(7)

(8)

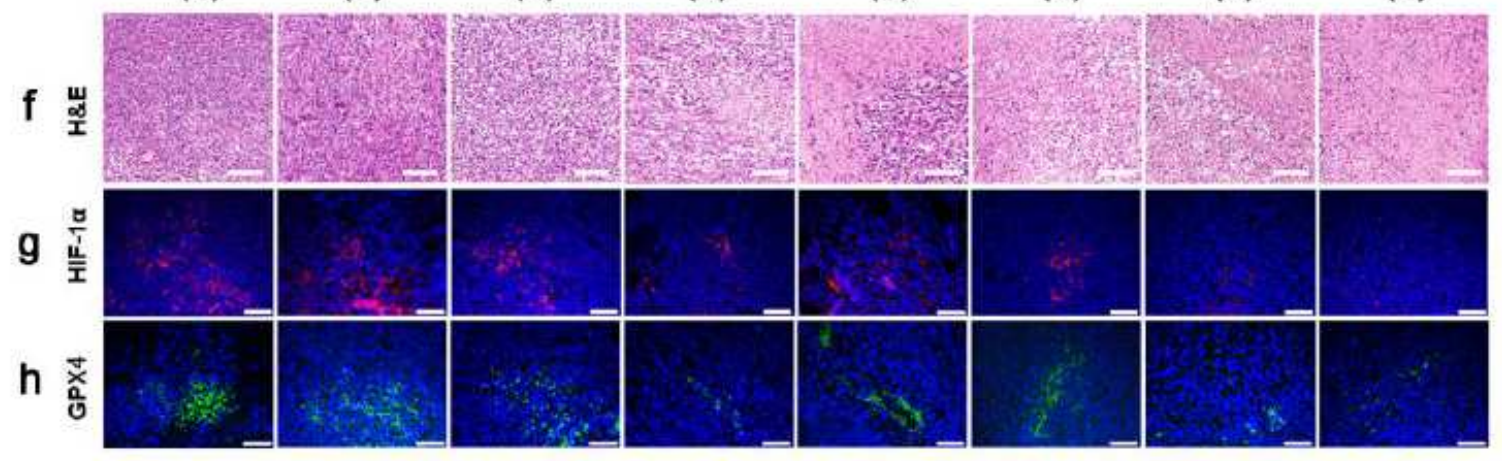

Figure 6

a) Treatment schedule of $\mathrm{H} 22$-tumour-bearing mice treated with different formulations. b) Changes in mice tumour volume during the entire treatment period. c) Changes in body weight of the mice during the entire treatment period. d) Tumour quality after treatment e) BALB/c mice treated with different conditions and corresponding tumours. f) H\&E staining of tumour tissue after treatment. Scale bar: 100 $\mu \mathrm{m} . \mathrm{g})$ Immunofluorescence image of HIF-1a in tumour tissue (red: HIF-1a, blue: nucleus). Scale bar: 50 
$\mu \mathrm{m}$. h) Immunofluorescence image of GPX4 expression in tumour tissue (green: GPX4, blue: nucleus). Scale bar: $50 \mu \mathrm{m}$.(1) PBS, (2) PBS+1000 mW/cm2, (3) PMM, (4) PMM+1000 mW/cm2, (5) PCMM, (6) $\mathrm{PCMM}+500 \mathrm{~mW} / \mathrm{cm} 2,(7) \mathrm{PCMM}+750 \mathrm{~mW} / \mathrm{cm} 2$ and (8) $\mathrm{PCMM}+1000 \mathrm{~mW} / \mathrm{cm} 2 .\left({ }^{\star}, \mathrm{P}<0.05 ;{ }^{* \star}, \mathrm{P}<0.01\right.$; $\star \star \star, P<0.001)$.

\section{Supplementary Files}

This is a list of supplementary files associated with this preprint. Click to download.

- Scheme1.png

- Supplementarymaterials.pdf 